\title{
El análisis perceptivo de la arquitectura histórica y su aplicación al Alcázar de Sevilla del siglo XI V
}

\section{The perceptive analysis of the historical architecture and its application to the 14th-century Alcazar of Seville}

\author{
Concepción Rodríguez Moreno \\ Laboratorio de Arquitectura y Arqueología de la Ciudad (LAAC-CSIC) \\ e-mail: concepcion.r.m@hotmail.com
}

\section{RESUMEN}

Este artículo trata de ilustrar el análisis de la arquitectura histórica desde un punto de vista tan propiamente humano como es la percepción. Hablamos de un tipo de análisis sensitivo, que permite aproximarse a cómo funcionaban o se entendían los edificios históricos desde una perspectiva plenamente vivencial, convencidos de que determinadas arquitecturas fueron construidas para propiciar experiencias perceptivas concretas en sus usuarios.

Sin embargo, en ocasiones es difícil plantear este tipo de análisis puesto que las arquitecturas estudiadas han sido transformadas o incluso han desaparecido. En estos casos, las reconstrucciones virtuales son realmente interesantes como vehículo para recuperar esos espacios arquitectónicos y "restaurar", en la medida de lo posible, las emociones, vivencias y significaciones que suscitarían entre los observadores de su tiempo.

Se exponen en primer lugar las claves conceptuales y metodológicas del análisis perceptivo, sirviendo como ejemplo su aplicación a la reconstrucción virtual del palacio construido por Pedro I en los Reales Alcázares de Sevilla del siglo XIV.

Palabras clave: Arqueología de la Arquitectura; Space Syntax; Estética medieval; Anastilosis Digital; Tecnologías 3D.

\section{ABSTRACT}

This text intends to illustrate the analysis of historical architecture from such a human point of view as it is perception. It is a sensitive analysis, which allows approaching how the historical builds worked and were understood from an existential perspective, since certain architectures were built to cause definite emotions to its users.

However, it is sometimes difficult to propose this type of analysis, because architectures have been usually transformed or have even disappeared. In these cases, virtual reconstructions are an interesting vehicle to recover these architectural spaces and "to restore", as far as possible, emotions, experiences and meanings that would provoke to its contemporary watchers.

The conceptual and methodological keys of perceptive analysis are explained, using as example its application to the virtual reconstruction of the palace built by the king Peter the First in the Alcazar of Seville in the 14th century.

Keywords: Archaeology of Architecture; Space Syntax; Medieval Aesthetic; Digital Anastylosis; 3D Technologies.

Recibido: 23/07/2012. Aceptado: 22/03/2013.

Cómo citar este artículo / Citation

Concepción Rodríguez Moreno 2013: “El análisis perceptivo de la arquitectura histórica y su aplicación al Alcázar de Sevilla del siglo XIV”, Arqueología de la Arquitectura, 10: e006. doi: http://dx.doi.org/10.3989/arq.arqt.2013.003

\section{Copyright}

(c) 2013 CSIC. Este es un artículo de acceso abierto distribuido bajo los términos de la licencia Creative Commons Attribution-Non Commercial (by-nc) Spain 3.0. 
Es obvio que sin un adecuado análisis arqueológico e histórico no podríamos hacer una lectura rigurosa y científica del patrimonio arquitectónico, pero con demasiada frecuencia esta lectura se limita a un acercamiento formalista y tipológico, que no llega a valorar ni a interpretar los factores que diferencian al hecho arquitectónico del resto de producciones artísticas o los significados y emociones que aquella arquitectura debió transmitir en su época. Quizá los arquitectos investigadores del patrimonio tengamos la culpa, puesto que nos hemos limitado a incorporar parte de nuestro bagaje instrumental al análisis de los edificios históricos, arrinconando muchas veces nuestro acervo conceptual. Perdemos de vista que los edificios deben ser concebidos como receptáculos donde se desarrolla la vida, como solución a una serie de condiciones previas y propósitos sociales, políticos, ideológicos, funcionales, etc. Olvidamos que la buena arquitectura es una obra de arte que debe disfrutarse con todos los sentidos ${ }^{1}$.

Aunque en demasiadas ocasiones se identifica con la lectura estratigráfica de los paramentos de un edificio o el análisis de materiales constructivos antiguos, a lo largo de su corta historia como disciplina autónoma, siempre ha sido ánimo de la Arqueología de la Arquitectura sentar las bases para un diálogo entre la arqueología y la restauración del patrimonio arquitectónico, plantear estudios alternativos y nuevos instrumentos y metodologías analíticas con los que maximizar la información contenida en los restos de edificios históricos, bien para profundizar en el conocimiento de las sociedades pasadas o bien para proyectar restauraciones de forma responsable ${ }^{2}$. Pensamos que la propuesta analítica que desarrollamos en este artículo se adapta perfectamente a esta filosofía, aportando un enfoque más desde el que observar e interpretar el patrimonio arquitectónico transformado o desaparecido.

\section{SOBRE LA ESENCIA, LA PERCEPCIÓN Y LA REPRESENTACIÓN DE LA ARQUITECTURA}

«El espacio (interior) es la esencia de la arquitectura». Así lo aseguraba el historiador August Schmarsow en su discurso La esencia de la creación arquitectónica. Aunque en ningún momento definía en qué consistía ese "espacio interior", este autor alemán de finales del siglo XIX, sí que hablaba de un "sentido" de espacio

\footnotetext{
1 Rasmussen, 1964, p. 9.

2 Quirós, 2002, pp. 28-29.
}

(Raumgefühl) que surgía, fundamentalmente, a partir de la experiencia sensorial y del movimiento del observador que recorre la arquitectura. Con un planteamiento claramente estético, Schmarsow daba especial importancia a la percepción de la arquitectura, al sentimiento de empatía que el observador desarrolla al «penetrar en el conjunto y, con una opinión puramente libre, entiende $y$ disfruta de todas sus partes» ${ }^{3}$.

De las teorías de Schmarsow se deduce, por tanto, que el factor que diferencia sustancialmente a la Arquitectura de otro tipo de artes es el espacio envuelto, el espacio interior en el cual los hombres viven y se mueven, y que éste, además de responder a cuestiones formales, también debe ajustarse al orden perceptivo que, de esa construcción, se quiere dar a la sociedad. Estas ideas tuvieron gran influencia en teorías analíticas del espacio arquitectónico como las de como Bruno Zevi (teoría visual) ${ }^{4}$, Francis Ching (teoría formal) ${ }^{5}$, Bill Hillier y Julienne Hanson (teoría social) ${ }^{6}$, etc.

Para nuestro estudio, una de las aportaciones más interesantes, pese a ser una de las más antiguas, son las que pueden extraerse de los capítulos que, en su libro Saber ver la arquitectura, Bruno Zevi dedica a reflexionar sobre la forma de representación del espacio arquitectónico. Explica cómo las plantas, alzados, secciones, perspectivas y fotografías son insuficientes para percibir el espacio arquitectónico, puesto que «toda obra de arquitectura, para ser comprendida y vivida, requiere el tiempo de nuestro recorrido» ${ }^{7}$. En este sentido, también expresa que la cinematografía y los recorridos subjetivos que la cámara marca al usuario que ve el video, son de inmenso alcance para la representación de los espacios arquitectónicos, aunque echa en falta en ella el resorte de participación completa del espectador, esa conciencia de libertad que advertimos en la experiencia directa del espacio. La conclusión final de este autor es que «en dondequiera exista una completa experiencia espacial para la vida, ninguna representación es suficiente. Tenemos que ir nosotros, tenemos que estar incluidos y tenemos que llegar a ser y a sentirnos parte y metro del organismo arquitectónico» ${ }^{8}$.

Los planteamientos de Zevi se pueden aplicar con facilidad a organismos arquitectónicos reales y tangibles,

\footnotetext{
Schmarsow, 1894.

4 Zevi, 1991.

${ }^{5}$ Ching, 2012.

${ }^{6}$ Hillier y Hanson, 1984.

7 Ibidem, p. 25.

8 Ibidem, p. 49.
} 
pero ¿qué ocurre si la arquitectura que queremos experimentar ha desaparecido? Nuestro caso de estudio por ejemplo, el Alcázar de Sevilla del siglo XIV, no puede visitarse ni ser percibido "in situ" tal y como era originalmente, puesto que muchos de los espacios medievales han sido transformados a lo largo de la historia9 ${ }^{9}$ En estos casos creemos que es especialmente útil recurrir a las anastilosis digitales, a la virtualidad de los modelos tridimensionales generados por ordenador.

En los años 40 del siglo XX, cuando Bruno Zevi escribía Saber ver la arquitectura, aún no se había producido la revolución informática ni se conocía la infografía. De haber sido así, no dudamos que este autor la habría incluido como otra de las formas de representar el espacio arquitectónico, o que habría defendido la utilización de las tecnologías de inmersión $3 \mathrm{D}^{10}$ para obtener la experiencia sensitiva del mismo. Aunque siempre incluirán cierto déficit sensorial y emotivo si las comparamos con la percepción directa de la realidad, probablemente sea éste el mejor medio para percibir la mayor parte de las cualidades que en su día definieron la esencia de un patrimonio arquitectónico transformado o desaparecido.

Desgraciadamente, en tanto esas tecnologías de inmersión no sean económica y técnicamente más accesibles $^{11}$, utilizarlas como herramienta habitual para el análisis perceptivo de la arquitectura histórica no pasará de mero planteamiento teórico. Lo que hoy sí que estamos en disposición de proponer como sistema de representación del espacio arquitectónico, de una forma asequible dado su bajo costo y la difusión casi universal del software, el hardware y los conocimientos informáticos necesarios, es la realización de animaciones audiovisuales a partir de las anastilosis digitales generadas mediante técnicas infográficas ${ }^{12}$.

\footnotetext{
${ }^{9}$ Los libros de Ana Marín Fidalgo, El Alcázar de Sevilla bajo los Austrias y Real Alcázar de Sevilla Bajo los Borbones. El reinado de Felipe V, y el escrito por M. ${ }^{a}$ Rosario Chávez González bajo el título El Alcázar de Sevillla en el siglo XIX son básicos para entender las múltiples modificaciones y reformas experimentadas por el conjunto monumental desde finales del siglo XIV hasta nuestros días. Ver Marín, 1990 y 2006; Chávez, 2004.

${ }^{10}$ Una de las tecnologías de inmersión 3D que parece ofrecer interesantes posibilidades en este sentido el Eon ICUBE, basado en el entorno de visualización CAVE. Su interfaz está formado por tres paredes blancas y un suelo, que componen una habitación cúbica blanca. Cada superficie brinda una proyección de alta resolución, así como imagen estereoscópica de un espacio. El espectador se encuentra en la habitación usando unas gafas polarizadas 3D, con pequeños marcadores que van en los marcos y que mueven la imagen de acuerdo al desplazamiento del usuario. En todo momento el usuario tiene su cuerpo como referencia, con lo que se aumenta el realismo de la escena y por tanto las sensaciones. http://www.eonreality.com/products_icube.html

11 Díaz Estrella, 2011, p. 32.

12 Almagro Gorbea, 2003, pp. 66-69.
}

Reconocemos que el análisis no será del todo completo, porque «una cosa es estar sentado en la butaca de un teatro y ver los actores que se mueven, y otra es vivir y actuar en la escena» ${ }^{13}$ pero, al menos, podremos experimentar los espacios a lo largo de la secuencia temporal de un recorrido, consiguiendo producir una representación del patrimonio perdido en la que recoger gran parte de los conceptos vinculados a la percepción de la esencia de la Arquitectura.

Llegados a este punto surgen nuevas preguntas: ¿Qué espacios arquitectónicos debemos representar y analizar? ¿Qué recorrido deberíamos seguir en nuestro análisis? ¿Podemos estar seguros de que nuestras percepciones son las mismas que las del observador para el que esas arquitecturas fueron construidas?

Establecer un marco metodológico a partir del que analizar legítimamente el espacio arquitectónico y que nos permita centrarnos en una serie de elementos y experiencias perceptivas básicas, es sin duda primordial para abordar este trabajo. Por otro lado, si no describimos, al menos someramente, cuáles eran los gustos estéticos, los valores espaciales, las experiencias perceptivas que la arquitectura del Alcázar del siglo XIV pretendía producir en su contexto histórico y social, nuestra descripción no sería del todo válida. Por tanto, dedicaremos los siguientes epígrafes de este texto a profundizar, por un lado, en los conceptos estéticos medievales y, por otro, a desarrollar algunos de los instrumentos de los que dispone la Arqueología de la Arquitectura para plantear el análisis perceptivo de los espacios arquitectónicos.

\section{LA PERCEPCIÓN DE LA ARQUITECTURA EN EL SIGLO XIV}

¿Qué sentiría un observador del siglo XIV al recorrer los espacios del Alcázar de Sevilla? ¿Qué impresiones querrían producir en él? Para ahondar en el simbolismo y las experiencias perceptivas que la arquitectura del palacio de Pedro I pretendería producir originalmente y poder interpretar convenientemente los espacios arquitectónicos virtuales generados, es necesario entender las particularidades del observador para el que esta arquitectura fue creada.

Desafortunadamente no hay críticos de arte medievales que nos hayan dejado sus pensamientos. La evaluación de la arquitectura hispana de este momento de la historia, basada en referencias internas, apenas si se ha intentado. Sin embargo, como expresan los historiadores del arte

\footnotetext{
${ }_{13}$ Zevi, 1991, p. 48.
} 
islámico Wilber y Golombek: «se pueden buscar ciertas claves de cómo la mente medieval enfrentaba el problema del juicio artístico. El lugar natural para buscar serían las escrituras filosóficas» ${ }^{14}$. La opción pasa, por tanto, por analizar el pensamiento filosófico medieval y especialmente la rama de la Estética, que en su sentido etimológico se define como «ciencia del sentir» y tiene por objeto el estudio de la esencia de la percepción y la belleza ${ }^{15}$.

La evidencia apunta a que la percepción de la belleza en el medievo, tanto en el mundo cristiano como en el musulmán, repite en general los postulados de los escritores clásicos ${ }^{16}$. Por ejemplo, en el siglo $\mathrm{X}$, el científico chií Ibn al-Haytham, en su Tratado de óptica, dedica un capítulo a la belleza como cuestión de percepción. Obviamente, este texto no puede considerarse una teoría islámica de la belleza, pero resulta muy interesante porque insiste en ciertos parámetros estética y perceptivamente relevantes para el arte islámico: medidas, proporciones, luz, etc., que armónicamente combinados generan placer visual al espectador ${ }^{17}$.

Asociados a la luz, las proporciones y las figuras, hay una serie de matices enumerados por Ibn al-Haytam: el color, la opacidad, la posición relativa, el orden, las dimensiones, la aspereza, etc. Estos matices, advierte, «carecen de belleza por sí mismos, y deben de estar integrados dentro de una composición armónica» ${ }^{18}$. Sin duda, con el empleo de los recursos citados por este ilustre matemático y físico se pueden configurar diferentes modos de ideación y composición con los que crear belleza ante los ojos de quien contempla el espacio arquitectónico y conseguir determinadas percepciones a través de la impresión de los sentidos.

Unos años después, el filósofo persa Al Gazali (S. $\mathrm{XI}$ ), al lado de la percepción y el conocimiento ordinarios, producto de los sentidos, coloca un conocimiento intuitivo, fruto de la ascética y la $\mathrm{fe}^{19}$. Se introduce así, de forma tangencial, la discusión en torno al tema de la belleza divina, básicamente abstracta. La belleza estética de las obras artísticas comienza a ponderarse en función a su aproximación a la perfección de la divinidad y de sus obras. La arquitectura es considerada bella cuando sus formas evocan imágenes de las cualidades divinas, como la luz o la luminosidad, la armonía, el orden, el

\footnotetext{
${ }^{14}$ Wilber y Golombek, 1988, p. 203.

15 Definiciones extraídas del Diccionario de la Real Academia Española 2001.

16 Seguró, 2008, p. 139.

17 Rodríguez, 2008, p. 100.

18 Puerta, 1997, pp. 701-711.

19 Véase Asín, 1935, vol. 1.
}

equilibrio o la proporción ${ }^{20}$. Ya en el lado cristiano, Santo Tomás de Aquino (S. XIII) recopilará, sin cambios notables, los pensamientos de estos filósofos musulmanes. La afirmación tomista más conocida en relación a la belleza vincula a ésta con la divinidad y la supedita a tres condiciones que debe incluir: la integridad o perfección, la proporción o armonía y la luminosidad o claridad («claritas, integritas, proportio») ${ }^{21}$. Si seguimos rastreando entre escritos de otros filosóficos medievales posteriores a los enumerados, comprobaremos cómo los conceptos de Luz, Simetría, Orden, Proporción o Equilibrio, se repiten incesantemente como cualidades de lo bello.

La búsqueda de la belleza en las construcciones del Alcázar de Sevilla probablemente se sustentaría en estos criterios estéticos. Por eso trataremos de tenerlos permanentemente presentes, como pautas para el análisis perceptivo de sus espacios arquitectónicos.

Por otro lado, y aunque no exista conexión directa con los conceptos estéticos medievales, entendemos que para juzgar adecuadamente las impresiones y simbolismos que la arquitectura del Alcázar trataría de transmitir originalmente es también muy importante considerar la personalidad, el contexto vital y los intereses particulares del promotor de la obra. Por ello nos propusimos conocer mejor al monarca castellano Pedro I, estudiando diversos artículos y obras literarias relacionadas con su perfil biográfico ${ }^{22}$.

Advertimos que la ideología política de Pedro I de Castilla se caracterizaba por el fortalecimiento de la figura del monarca frente a otros estamentos y la creación de diversas instituciones gubernamentales relacionadas con la justicia, el erario público o el ejército. Sin duda Don Pedro debía encontrar los medios para transmitir claramente la legitimidad y la supremacía del poder que pretendía asumir. También descubrimos a un monarca culto y extremadamente interesado en la arquitectura como demuestran las numerosas empresas edilicias que acometió durante su corto reinado ${ }^{23}$.

De esta parte de la investigación previa concluimos que este soberano encontró en la edificación de sus palacios, y especialmente en la del levantado en el Alcázar de Sevilla,

\footnotetext{
${ }^{20}$ Rodríguez, 2008, p. 101.

${ }^{21}$ Beardsley y Hospers, 1997, p. 42; Eco, 1997, p. 108.

22 Véase López de Ayala, 1779, t. 1; Moya, 1974; Estow, 1995; Díaz Martín, 1997.

${ }^{23}$ Es innegable la frenética actividad arquitectónica desarrollada por el monarca castellano, que en los diecinueve años de su reinado construyó palacios en Astudillo (Palencia), Tordesillas (Valladolid), Carmona y Sevilla, pero que también dedicó importantes sumas de dinero al levantamiento y reedificación de numerosos edificios religiosos. Cómez, 2008, p. 50.
} 
una forma de crear escenarios acordes con la idea de un poder real absoluto, con los que además se reforzaran conceptos como el origen divino, la legitimidad y la supremacía de ese poder frente a los enemigos de la corona.

\section{LA ARQUEOLOGÍ A DE LA ARQUITECTURA Y EL ANÁLI SI S ESPACI AL}

Desde finales de los años 80 y especialmente en el mundo anglosajón, se vienen desarrollando una serie de herramientas de análisis espacial que, agrupadas bajo la ambigua denominación de space syntax, pretenden interpretar determinados aspectos sociales e ideológicos contenidos en el diseño y distribución de los espacios arquitectónicos. Aunque concebida originalmente por Bill Hillier y Julienne Hanson en la University College de Londres $^{24}$ como una herramienta para ayudar a los arquitectos a simular los posibles efectos sociales de sus diseños urbanos, esta metodología se ha aplicado también a otras materias como la sociología, la antropología, la ingeniería civil o la Arqueología de la Arquitectura ${ }^{25}$.

La idea general en esta "sintaxis espacial" es que los espacios arquitectónicos se pueden desglosar en componentes, analizados como redes de elección y luego representados como mapas y gráficos que describen la relación de conectividad e integración de los mismos, revelando el estilo de vida de sus usuarios. En sus versiones actuales ${ }^{26}$ esas representaciones combinan los mapas de líneas ${ }^{27}$, los mapas de convexidad ${ }^{28}$, los análisis de visibilidad ${ }^{29} \mathrm{o}$ los análisis gamma ${ }^{30}$.

\footnotetext{
${ }^{24}$ Las técnicas analíticas se asocian al marco teórico presentado por primera vez en The Social Logic of Space (Hillier y Hanson, 1984), a partir del cual se ha formado un programa de investigación a nivel internacional. (Ver http:// www.bartlett.ucl.ac.uk/casa)

25 Bermejo, 2009, pp. 48-54.

26 Batty, 2004.

${ }^{27}$ En los mapas de líneas o mapas axiales se trazan el conjunto mínimo de líneas rectas de la mayor longitud y de movimiento no obstruido que cruzan e interconectan todos los espacios abiertos (convexos) de un sistema urbano.

${ }^{28}$ Un espacio convexo es tal que una línea dibujada desde una parte de él a cualquier otra no salga nunca fuera del polígono. Los mapas de espacio convexo representan los espacios disponibles para la interacción social.

${ }^{29}$ El análisis de la visibilidad permite definir el grado de privacidad de los espacios de una construcción arquitectónica cerrada. Se realiza en función de la situación del individuo que percibe el interior de la estructura desde un punto de vista concreto, que se corresponde con el centro del umbral de acceso a cada estancia o espacio. Ver Braaksma y Cook, 1980.

${ }^{30} \mathrm{El}$ análisis gamma cuantifica las profundidades y permeabilidades de los espacios, así como la facilidad de acceso, valorando el grado de dependencia de unos espacios respecto a otros, el control de acceso y el movimiento que permiten entre ellos. Los elementos clave en este análisis son los umbrales que separan / comunican los espacios entre sí, pues actúan como controladores de paso a determinado ambiente. Ver Foster, 1989.
}

Aunque creemos que estas herramientas pueden ser de utilidad para identificar las configuraciones espaciales más relevantes, no sirven para llegar a interpretarlas adecuadamente porque, como exponíamos en líneas anteriores, mapas y gráficos no son suficientes para describir un espacio arquitectónico en su totalidad. Por este motivo nos propusimos trasladar, en la medida de lo posible, los fundamentos teóricos sobre los que se basan estas técnicas analíticas bidimensionales a una animación en video y combinarlos con otros conceptos relativos a las teorías de la percepción visual ${ }^{31}$, la disciplina de análisis de formas arquitectónicas o el análisis de accesos ${ }^{32}$ y circulaciones $^{33}$, que juzgamos son fundamentales para poder explicar la experiencia perceptiva generada al recorrer un espacio arquitectónico.

\section{Los mapas axiales y de convexidad en la elección del recorrido de la animación}

En una imagen estática, cada espectador puede pasar la mirada siguiendo el itinerario de lectura que prefiera. A lo sumo, el autor de la imagen puede tratar de inducir este itinerario utilizando determinados recursos que faciliten su seguimiento, pero nunca podrá predeterminarlo. Por el contrario, en una animación, la secuencia de lectura está establecida de antemano por su realizador, que selecciona la estructura argumental y el guión que mejor se adapten al orden secuencial de los conceptos que desea exponer.

En nuestro caso debíamos plantear un hilo argumental que explicase, lo mejor posible, la esencia arquitectónica del palacio de Pedro I en los Reales Alcázares. Debíamos concebir una secuencia animada de los espacios que generasen las percepciones más intensas y significativas en un observador del siglo XIV. Por fortuna, la propia arquitectura establece secuencias perceptivas a través de las circulaciones y recorridos que relacionan los distintos espacios pero, además, en el caso de una arquitectura monumental como la que nos ocupa, es frecuente que exista un recorrido especialmente relevante, un itinerario que encadene los ámbitos espaciales y simbólicos más representativos del conjunto y vaya

\footnotetext{
31 Especialmente los derivados de la psicología de la Gestalt. Arnheim, 2002.

${ }^{32}$ El análisis de accesos tiene como premisa que una de las formas de analizar cómo se percibe un espacio arquitectónico es por medio del movimiento hacia él, el recorrido que hacemos tanto para aproximarnos como para pasar de un espacio a otro dentro de la construcción. Ver Faulkner, 1964.

33 Se trata de identificar el "hilo perceptivo" de una construcción a través del movimiento en sus espacios, reconociendo espacios preeminentes en el esquema general de circulación, bien sea por ser espacios distribuidores o bien porque estos se encuentran al final de un recorrido. Ver Ching, 2002, pp. 228-252.
} 


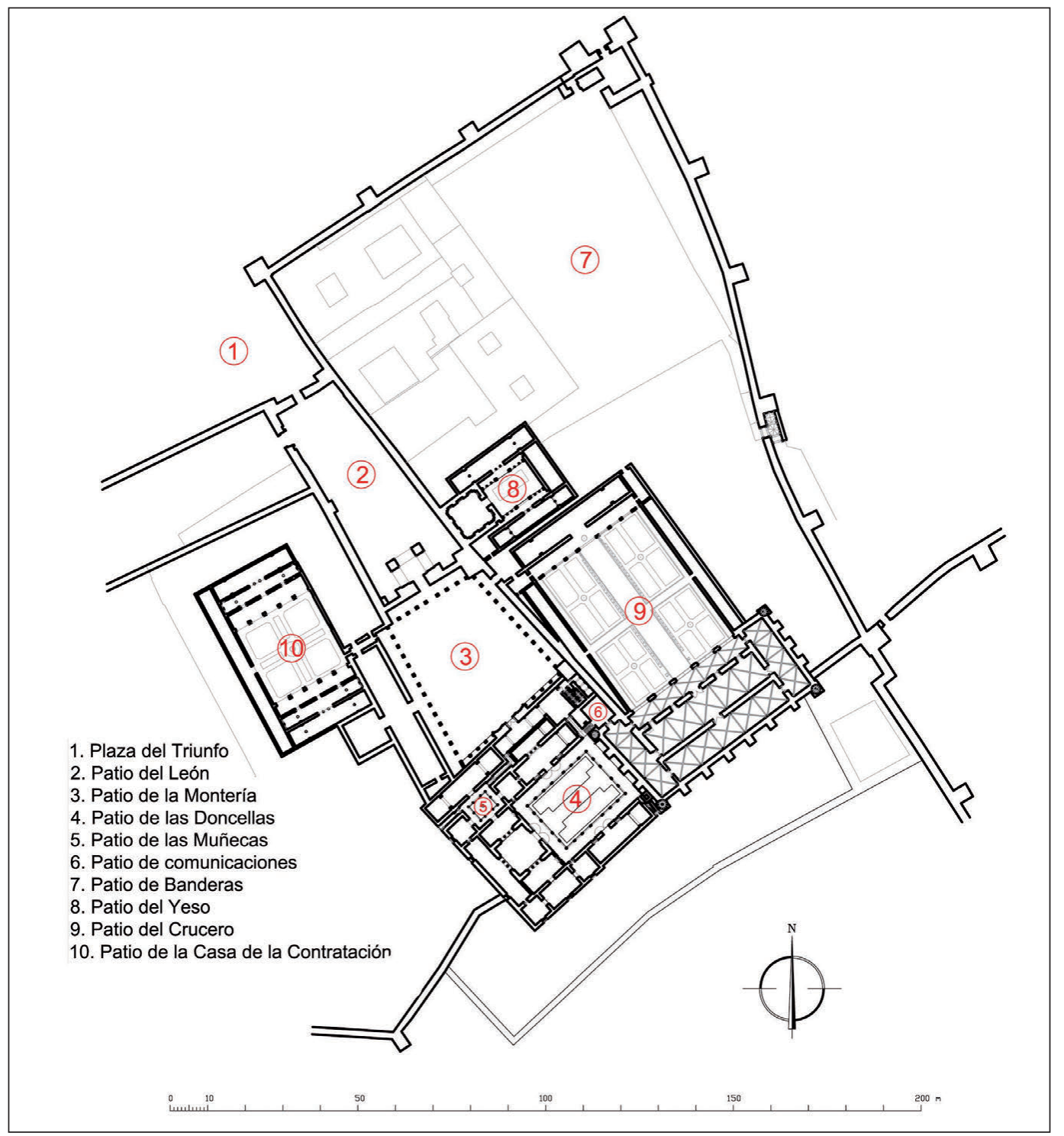

Figura 1. Planimetría del Alcázar de Sevilla en el S. XIV, dibujada a partir de la hipótesis de Antonio Almagro. (Almagro Gorbea, 2007b)

conduciendo al observador hasta el corazón de la obra arquitectónica.

Nos dispusimos, por tanto, a identificar ese recorrido principal del Alcázar de Sevilla en el siglo XIV que iba a servir de hilo argumental a nuestra secuencia animada. Para ello recurrimos a los mapas axiales y de convexidad del la sintaxis espacial, trazados sobre la hipótesis reconstructiva del conjunto monumental sevillano (Fig. 1).

Gracias a estos gráficos (Fig. 2), pudimos comprobar que la línea recta de mayor longitud de todas las trazadas que interconecta, además, la mayor parte de los espacios convexos del Alcázar de Sevilla, coincide con el recorrido de acceso al palacio privado de Pedro I, un eje visual y de movimiento que se inicia en la Plaza del Triunfo, franquea la Puerta del León, atraviesa el patio del mismo nombre y continúa por la Puerta y el Patio de la Montería hasta llegar a la puerta del palacio mudéjar. Nos parece muy interesante destacar que, de no ser por el muro que configura el cierre meridional del vestíbulo, esta alineación conectaría con el centro del Patio de las Doncellas ${ }^{34}$, siendo éste último el único espacio convexo del Alcázar que se encuentra rodeado por ejes

\footnotetext{
${ }_{34}$ De hecho, la apertura de una comunicación axial entre el Patio de la Montería y el Patio de las Doncellas ha sido siempre una idea recurrente. Si atendemos al plano de 1608 atribuido a Vermondo Resta, en el que se describían una serie de reformas que debían acometerse en el Alcázar del siglo XVII, podemos comprobar cómo aparece "grafiado" un hueco en el muro Sur del vestíbulo del palacio de Don Pedro, alineado con el eje principal de acceso. Desconocemos si ese hueco llegó a ejecutarse y si lo proyectado era una ventana o una puerta de paso. Posteriormente, y a través de la descripción de Don Miguel de Olivares y Guerrero de los reparos acometidos entre 1805 y 1806, sabemos que se abrió «puerta de entrada al muro interior enfrente de la puerta principal, franqueándole la entrada al gran patio principal». La huella de este hueco, hoy tapiado, aún se mantiene en forma de gran rehundimiento. Chávez, 2004, pp. 32-33.
} 


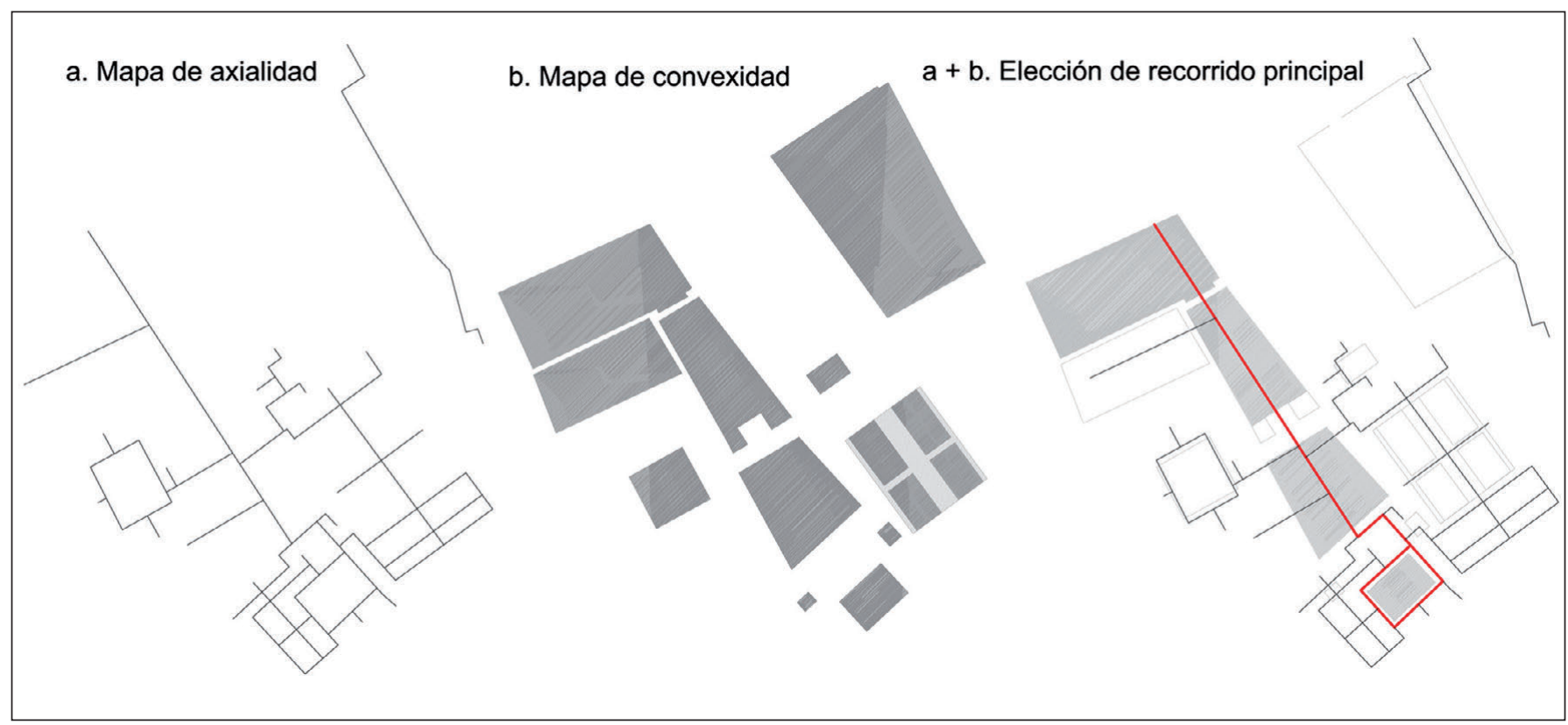

Figura 2. Mapa de axialidad (a) y mapa de convexidad (b) del Alcázar de Sevilla en el S. XIV. A partir de ellos se determina la circulación principal del conjunto arquitectónico $(a+b)$

perimetrales de circulación secundarios. Sin duda el quiebro del recorrido producido en el interior del palacio está condicionado por razones de privacidad, así que creemos que el Patio de las Doncellas debe identificarse con el núcleo espacial del conjunto palatino.

Decidimos por tanto que el hilo argumental de la descripción animada al que nos referíamos anteriormente, seguiría el principal itinerario protocolario del complejo palatino, aquel que tras recorrer tres de los espacios convexos más importantes del Alcázar (Patio del León, Patio de la Montería y Patio de las Doncellas) aproximaba al súbdito hasta el ámbito imbuido de la máxima intensidad perceptiva de todo el conjunto edificado en tiempos de Pedro I.

\section{Los mapas de visibilidad y el movimiento del objetivo de la cámara}

Habíamos definido la trayectoria de movimiento de nuestra cámara, pero ¿qué debíamos mirar? ¿Hacia dónde orientar su objetivo? Pensamos que la elaboración del mapa de visibilidad del recorrido de la animación podía ayudarnos en esta tarea (Fig. 3).

Puesto que los umbrales de ingreso al Patio de la Montería o el Patio de las Doncellas son conceptual y formalmente más complicados que una simple puerta de paso entre distintos espacios, decidimos trazar en ellos dos conos visuales diferentes, el primero correspondiente al momento en que el observador se ubicase en el punto central del acceso completo (conos verde oscuro del gráfico), el segundo dibujado a partir del centro del último umbral que debía atravesarse (conos verde claro).

Gracias a este mapa pudimos constatar que la Puerta de la Montería o la fachada del Palacio de Don Pedro son los elementos visualmente más importantes de todo el recorrido, puesto que se percibirían independientemente de la posición ocupada por el observador en cada uno de los umbrales de acceso, pero también observamos que, estando el observador a punto de ingresar en el Patio de la Montería o el Patio de las Doncellas, determinadas piezas reclamarían su atención al ser visualizadas de forma tangencial: la qubba de la Montería en el primer caso, la qubba de la Media Naranja en el segundo. Resolvimos que serían éstos los hitos arquitectónicos hacia los que dirigiríamos nuestra mirada.

En conclusión, los datos aportados por las herramientas propias de la sintaxis espacial nos permitieron plantear la secuencia más adecuada para nuestra animación. Por otro lado, disponíamos también de los términos básicos para redactar el guión de la misma: los conceptos estéticos medievales asociados al concepto de arquitectura bella. Sólo nos restaba levantar los escenarios en los que se desarrollaría la acción. Expondremos de forma muy somera y en grandes líneas los puntos de referencia metodológica seguidos durante la elaboración del modelo reconstructivo del Alcázar de Sevilla en el siglo XIV. 


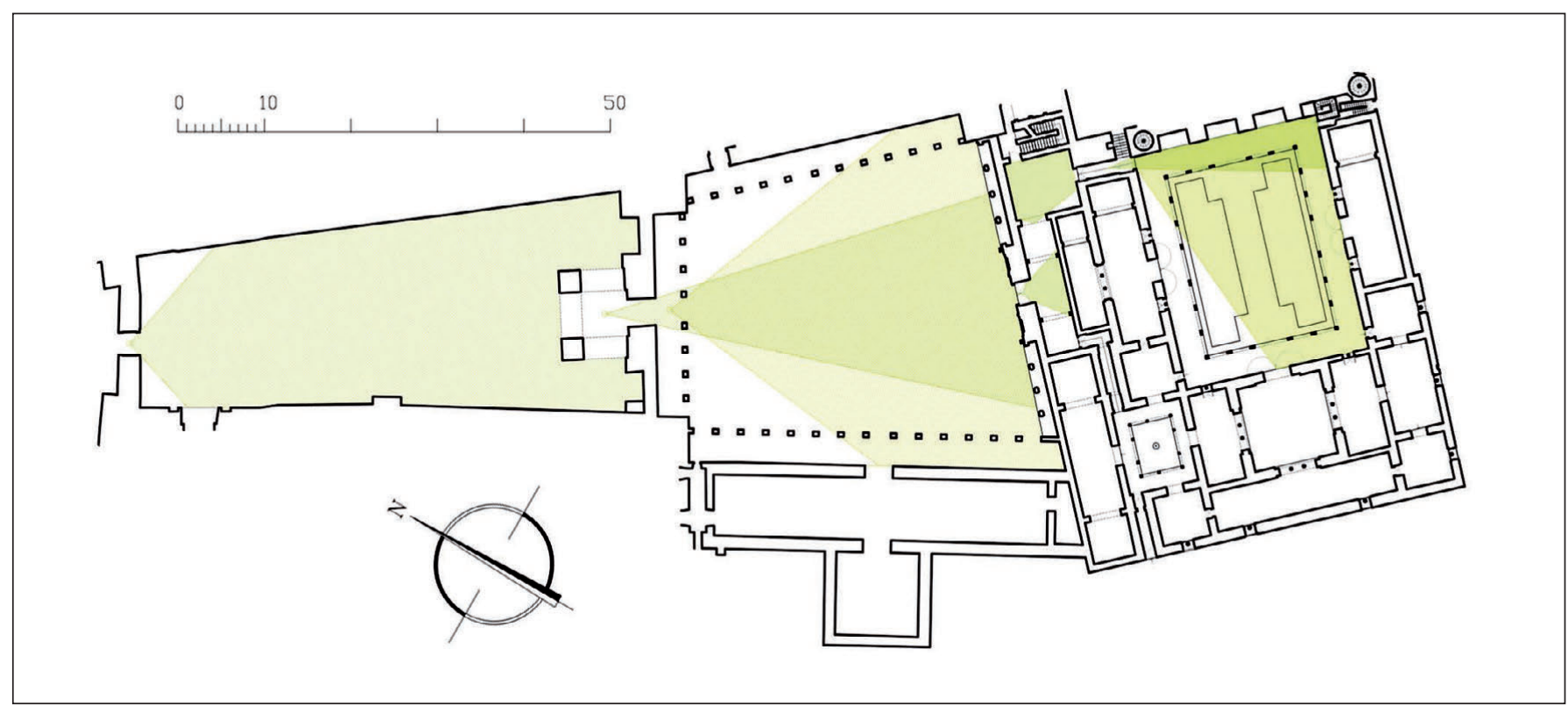

Figura 3. Mapa de visibilidad del recorrido principal. A partir de él se localizan los hitos arquitectónicos que marcarán la orientación del objetivo de la cámara

\section{METODOLOGÍ A BÁSICA DE ELABORACIÓN DEL MODELO PARA LA ANASTI LOSIS VI RTUAL}

En primer lugar se abordó la recopilación de la bibliografía y de los datos métricos y planimétricos disponibles. En esta fase se prestó una especial dedicación al registro de fotogrametrías y levantamientos del edificio actual, al análisis de imágenes fotográficas y grabados antiguos, así como a la búsqueda documental de reconstrucciones ideales, narradas o dibujadas, dotadas de cierto valor científico ${ }^{35}$.

A partir de esta documentación se procedió a elaborar los planos digitales de las hipótesis reconstructivas, centradas en el estado cronológico del edificio en tiempos de Don Pedro ${ }^{36}$, continuando con el modelado tridimensional de estas hipótesis mediante programas de carácter vectorial como AutoCad y 3DStudio y la posterior aplicación de texturas realistas, iluminación natural y efectos visuales adecuados. Con ello tratábamos de caracterizar el espacio arquitectónico a través

\footnotetext{
35 Aunque la documentación barajada en esta primera fase fue ingente, señalaremos como especialmente relevantes la descripción del Alcázar realizada por Rodrigo Caro en el siglo XVII (Caro 1634), las investigaciones de José Gestoso en el XIX (Gestoso 1889) o las publicaciones recientes de Tabales (2001; 2003; 2005; 2006; 2010), Marín (1990; 2006), Cómez (1989; 1996; 2006; 2008) y Almagro Gorbea (2000; 2003; 2005; 2006; 2007a; 2007b; 2009).

${ }^{36}$ La elaboración de estas hipótesis reconstructivas era uno de los propósitos del proyecto de investigación Los palacios de Pedro I de Castilla (BHA 200303983), dirigido por Antonio Almagro Gorbea entre los años 2003 y 2006 en la Escuela de Estudios Árabes de Granada (CSIC).
}

de sus atributos geométricos, de textura, iluminación y contexto.

Para el modelado geométrico admitimos un cierto nivel de tolerancia con respecto a la precisión de la planimetría vectorial inicial, al entender que los pequeños desajustes con respecto a las coordenadas y las medidas originales no influirían en la percepción final del modelo. Intentamos, por tanto, homogeneizar los elementos geométricos "casi idénticos" o aquellos que por su tamaño no iban a ser percibidos en la animación, para optimizar la eficiencia del proceso.

Para la texturización de los volúmenes geométricos generados utilizamos, por norma general, texturas reales extraídas de la rectificación de fotografías actuales del conjunto sevillano, obteniendo las coordenadas necesarias para ello de los archivos vectoriales correspondientes. Cuando los objetos tenían una textura con relieve, recurríamos en muchas ocasiones a la aplicación de mapas "bump", mapas que los motores de renderizado utilizan para modificar la reflexión de la fuente de luz sobre el objeto y dar apariencia de rugosidad en el mismo, evitando así incrementar el peso geométrico de la maqueta digital.

En lo referente a la iluminación del modelo, optamos por utilizar una luz direccional que simulase el sol, colocándola en distintas posiciones para imitar su movimiento a lo largo del día y combinándola con luces omnidireccionales que no proyectasen sombras, tratando de lograr así una mayor gradación lumínica entre los espacios exteriores 
y las salas en penumbra. Para reproducir la impresión de deslumbramiento que nuestros ojos experimentan cuando pasamos de un interior oscuro a un exterior soleado, empleamos el efecto de volumen de luz ("volume light") aplicado a luces direccionales de pequeña intensidad localizadas en puertas de salida al exterior y pasillos que desembocan en patios.

Evaluado visualmente el modelo obtenido a través de imágenes fijas o de síntesis ${ }^{37}$ y realizados los ajustes oportunos, podíamos por fin proceder al planteamiento de la animación de los espacios arquitectónicos más representativos del Alcázar de Sevilla en el siglo XIV, escogiendo para ello una cámara con un punto de vista situado a una altura similar a la de un hombre medio $(1,70 \mathrm{~m})$, con un objetivo de $28 \mathrm{~mm}$ que reproduce aproximadamente los $60^{\circ}$ del foco visual humano, desplazándose a una velocidad de $1,40 \mathrm{~m} / \mathrm{s}$ sobre la trayectoria obtenida a partir de la aplicación de las herramientas de la sintaxis espacial, y grabando una película standard con frecuencia de 24 fotogramas $/ \mathrm{s}^{38}$.

\section{RESULTADOS: LA EXPERI ENCI A SENSI TI VA A TRAVÉS DE LA ANI MACI ÓN DEL MODELO VI RTUAL ${ }^{39}$}

\section{El recorrido público de acceso al palacio [Secuencia 1]}

Los seres humanos sentimos una extraña fascinación por los ejes visuales por el hecho de que vemos en línea recta. Cualquier alineación de tres o más objetos, uno de los cuales es nuestro propio ojo, parece estar investida de un significado particular.

En la animación del modelo virtual puede comprobarse cómo la nueva entrada axial al Alcázar de Sevilla, ideada en tiempos de Don Pedro, estaría dotada

\footnotetext{
37 Se entiende por elaborado de síntesis o imagen sintética digital al producto de procesar un conjunto de polígonos de un modelo informático de arquitectura, sometidos a unas condiciones virtuales de iluminación y contexto. Fernández y González, 2002, p.529.

${ }^{38}$ En el modelo estándar cinematográfico la visualización está supeditada a la naturaleza lineal de la cinta cinematográfica, que condiciona la observación del espectador a la cadencia constante de los 24 fotogramas por segundo, es decir, la proyección tiene una sola dirección y a una velocidad constante. Las tecnologías de visualización disponibles actualmente (CD, DVD, Blu-Ray, etc.) aportan algunos cambios desde el momento en que el espectador puede variar la velocidad y el sentido de la proyección, permitiéndole la visualización parcial del documento audiovisual, repitiendo tantas veces la misma escena como sea necesario. Susperregui y Arranz, 2007, p. 50.

39 Dada la imposibilidad de reproducir la animación para ilustrar este texto, se recurrirá al empleo de gráficos compuestos por un conjunto escogido de fotogramas mostrados en secuencia ("storyboard" en lenguaje cinematográfico), con objeto de que sirvan de guía para entender la narración.
}

de un interesante planteamiento perceptivo: una "visión seriada" ${ }^{40}$ que, mediante una concatenación de espacios comprimidos y descomprimidos alternos, potenciaría el carácter dinámico del recorrido (Fig. 4). El uso del contraste (pequeño-grande, oscuro-luminoso, lleno-vacío, etc.) entre las puertas y los patios excitaría al observador y haría que la percepción del espacio fuese más dramática. Es un hecho que al «comparar lo disímil, aguzamos el significado de ambos opuestos» ${ }^{41}$. Así pues, de la misma manera que si tocamos algo rugoso y a continuación algo liso, lo liso parece más liso aún, con esta estrategia los patios se percibirían aún más amplios y luminosos, generando en el observador la sensación de que el espacio se dilata indefinidamente hasta el foco visual que es la puerta de acceso al palacio mudéjar (Fig. 5).

El primer elemento de esta composición axial es la puerta del León (Fig. 6). Al formar parte del recinto amurallado exterior, expresa un carácter marcadamente tectónico, una apariencia pretendidamente sólida y resistente. Esta sensación se ve acentuada por el uso de la piedra como material predominante y por los rotundos volúmenes prismáticos que conforman las dos torres que la enmarcan. Pese a no ser las torres idénticas en sus dimensiones ni en su configuración espacial, pese a no existir una simetría geométrica ni un trazado ortogonal en esta puerta, la percepción que se tiene del conjunto es la de una composición equilibrada y simétrica. Esta apariencia es el resultado de una adecuada armonía de los pesos visuales de los distintos elementos que la componen, del efecto de continuidad de textura entre la torre izquierda y el paño de muralla, que la hace aparentar una anchura mayor de la real y equipararla a la de la torre derecha y de la utilización en ambas de cuatro merlones como remate superior, mucho más esbeltos en la torre derecha. Por su parte, el hueco de esta puerta constituiría el nexo de unión espacial entre el exterior del Alcázar y el Patio del León (Fig. 7).

El Patio del León se experimentaría en el siglo XIV como un ámbito extraordinariamente tenso, pleno de recursos escenográficos. Por ejemplo, el carácter uniforme y oscuro del acabado de los muros laterales o el ritmo repetitivo introducido por el almenado servirían para crear un fondo pasivo que acentuaría, también por contraste, los elementos más relevantes de la composición: el baldaquino de piedra que conformaría la Puerta de la Montería en época medieval ${ }^{42}$ y más allá la fachada

\footnotetext{
${ }^{40}$ Cullen, 1974.

${ }^{41}$ Dondis, 1992, p. 114.

${ }^{42}$ Almagro Gorbea, 2005, p. 62; Tabales, 2006, pp. 27-28.
} 


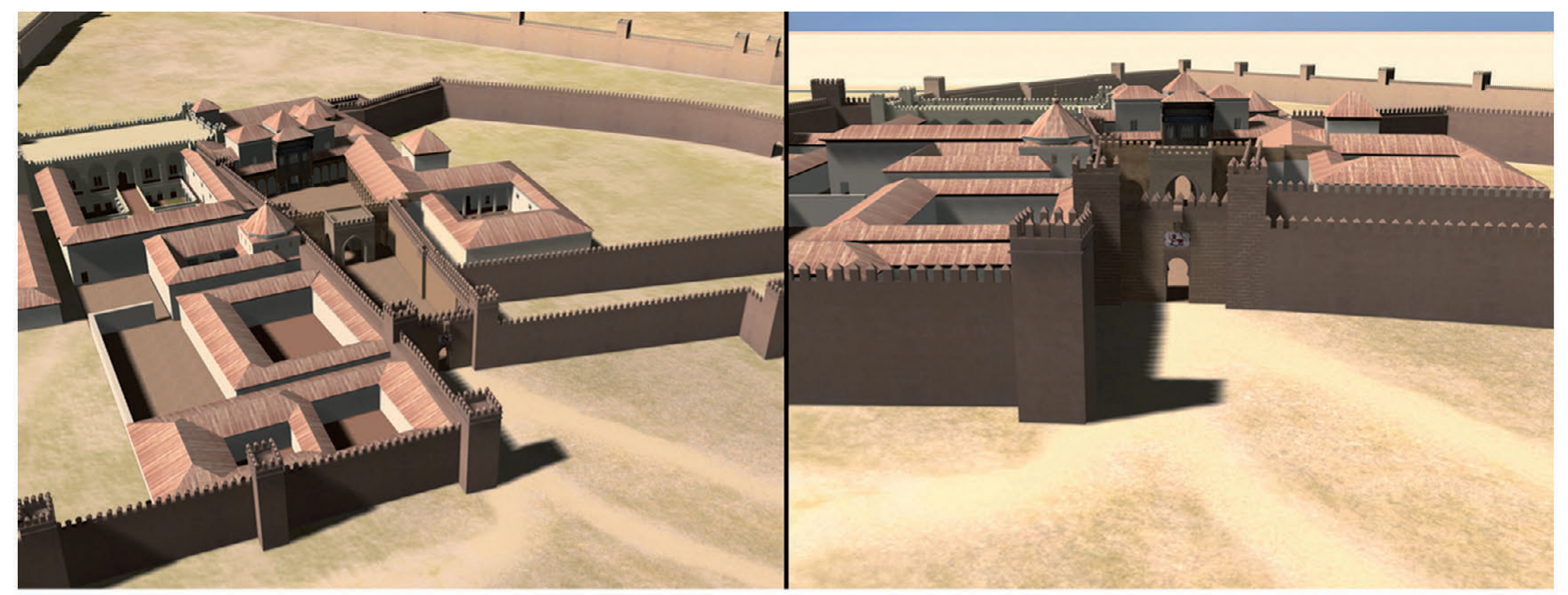

Figura 4

Figura 5

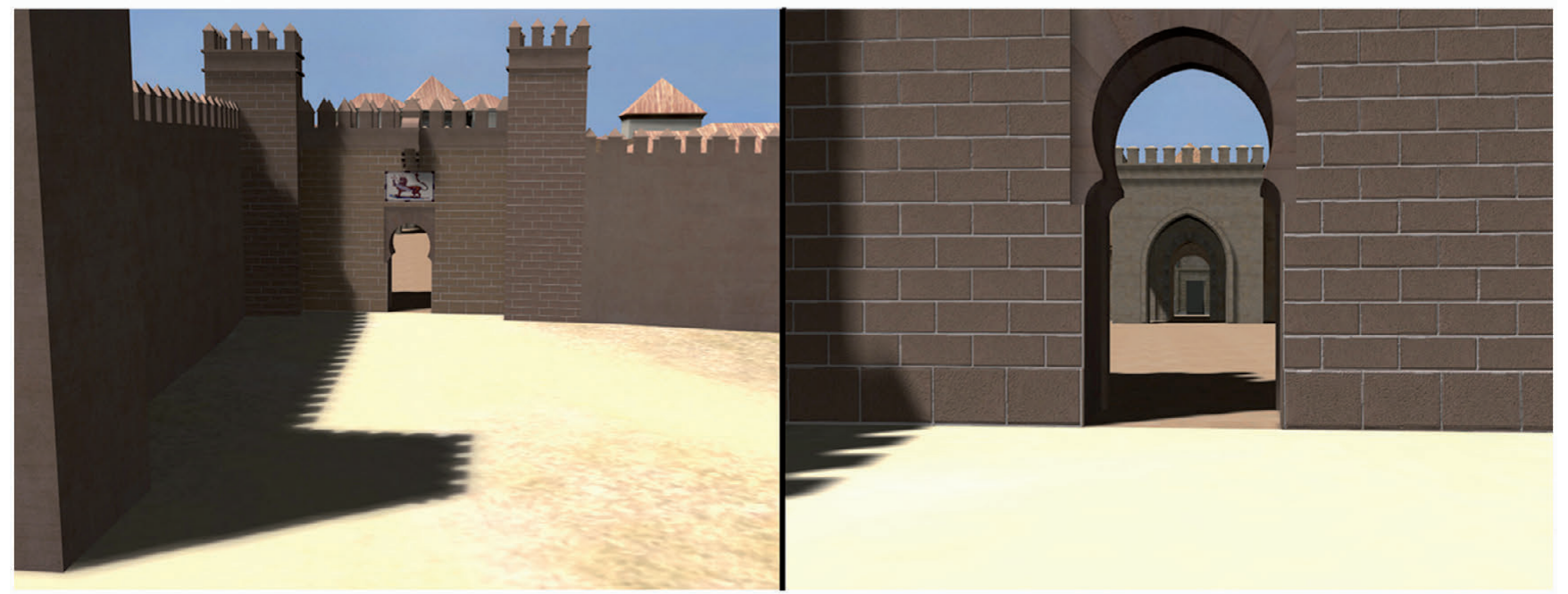

Figura 6

Figura 7

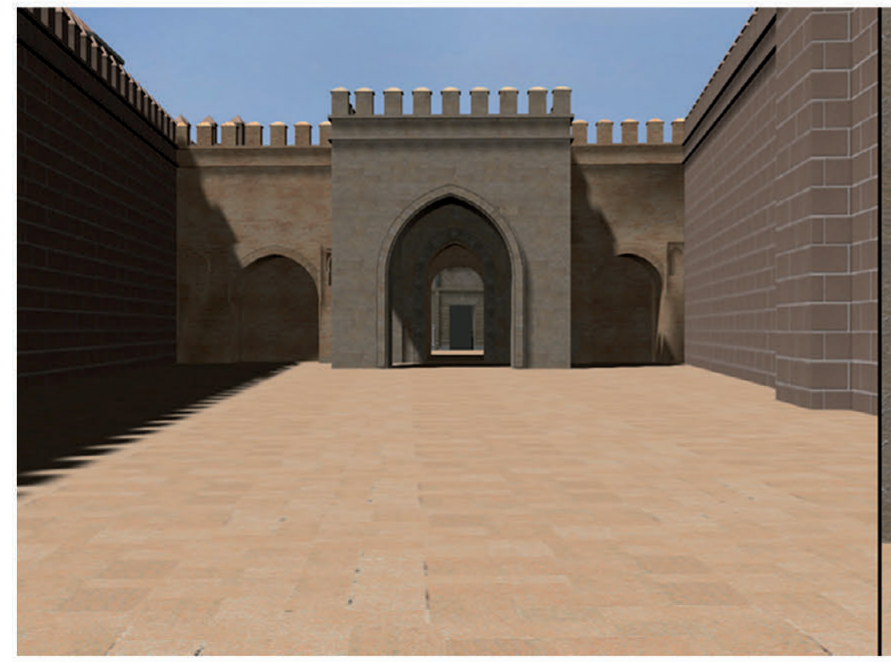

Figura 8

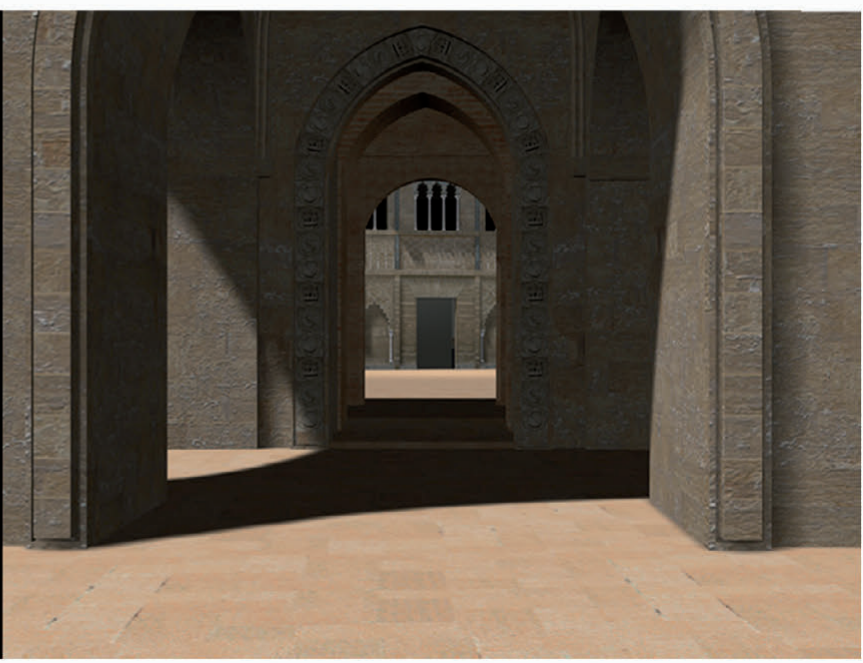

Figura 9

Figuras 4 a 9 [Secuencia 1]: El recorrido público de acceso al palacio 


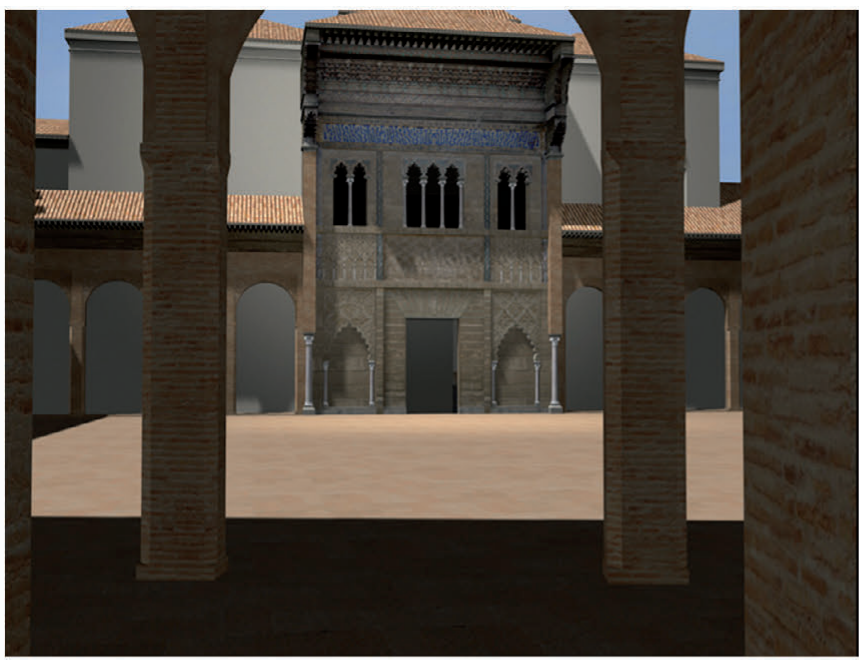

Figura 10

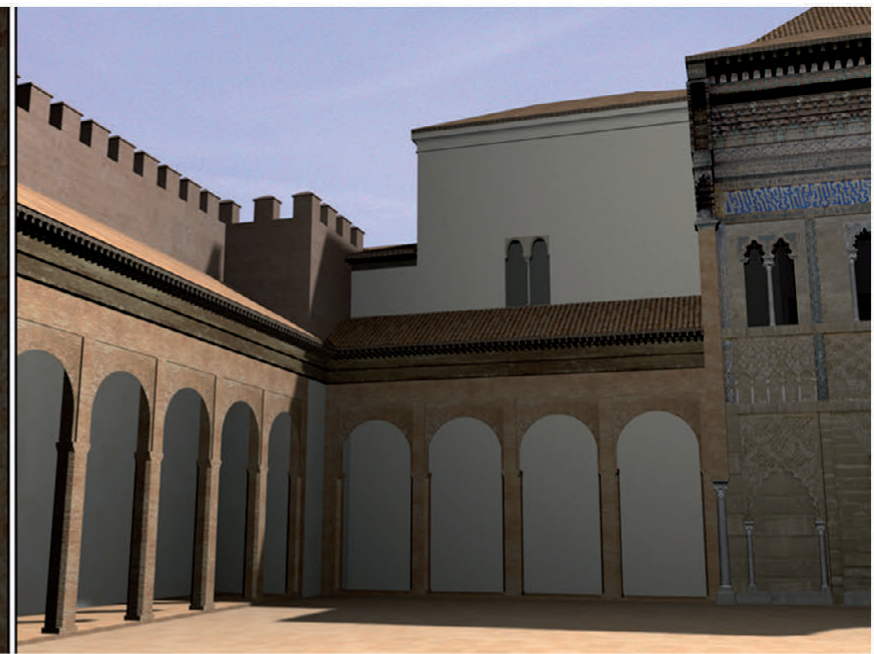

Figura 11

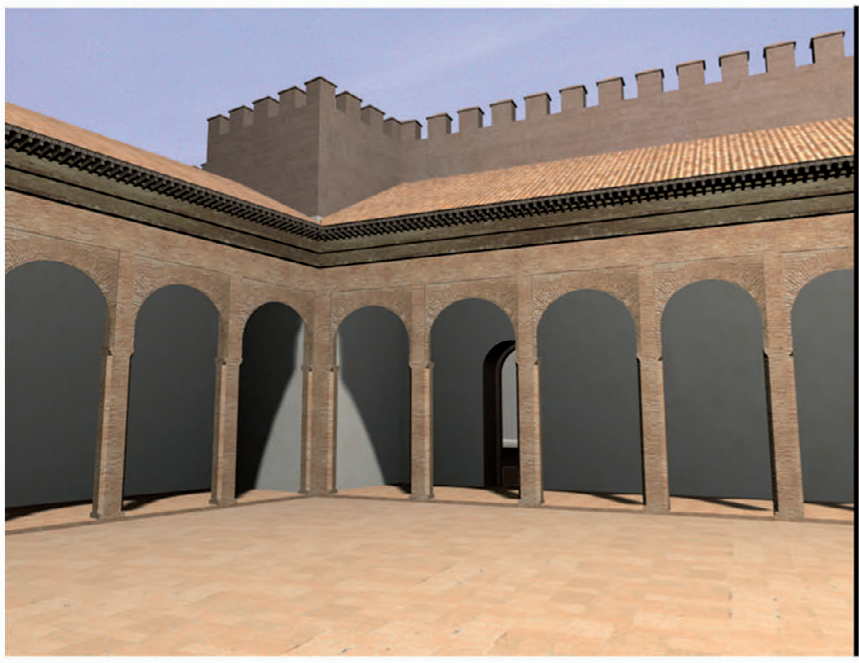

Figura 12

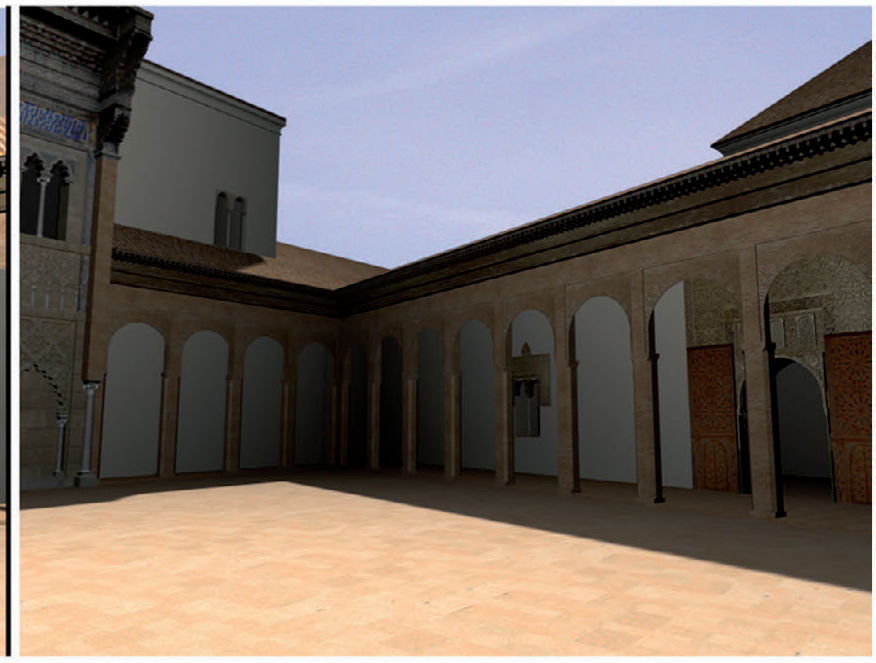

Figura 13

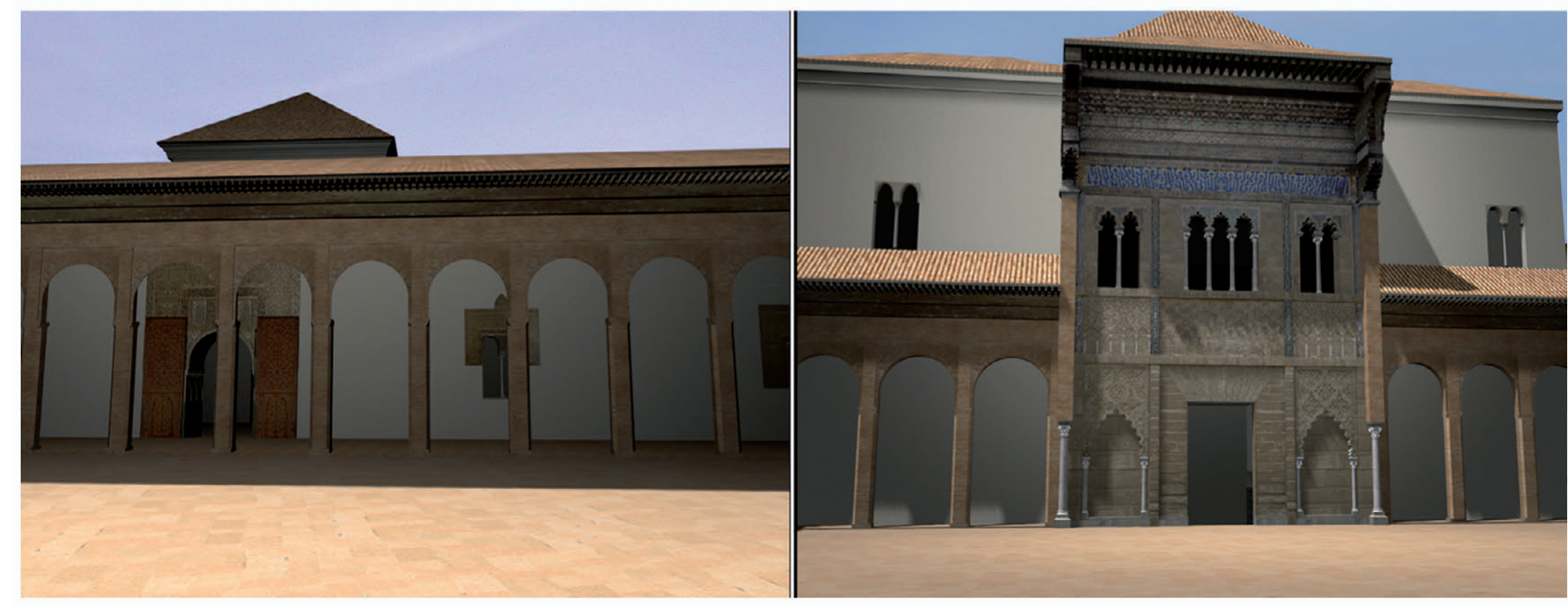

Figura 14
Figura 15

Figuras 10 a 15 [Secuencia 1]: El recorrido público de acceso al palacio 
regia, llevando la mirada y el movimiento hacia ellos (Fig. 8).

Serviría este baldaquino para proyectar la autoridad del monarca hacia unos súbditos que, al franquearlo, creerían mermar ante su monumentalidad puesto que esta puerta estaría pensada para constreñir todo lo posible la percepción antes de experimentar la explosión espacial y sensitiva que se produciría al entrar en el Patio de la Montería (Fig. 9). En ella se generarían, además, una secuencia de claroscuros que ayudaría a enmarcar el fondo luminoso de la fachada principal del palacio de Don Pedro (Fig. 10).

Por su parte, el espacio abierto del Patio de la Montería debió entenderse como núcleo del nuevo proyecto del Alcázar. En él convergerían las circulaciones principales y se separaría la zona pública de la privada $\mathrm{y}$, a diferencia del dinamismo lineal que caracterizaba al Patio del León, sería un espacio estático, concebido posiblemente para realizar las audiencias públicas del monarca. Es probable que este patio estuviese porticado en todo su perímetro en época medieval ${ }^{43}$, introduciendo en la composición una simetría bilateral que ralentizaría la velocidad del movimiento del observador, instándole a realizar una lectura helicoidal del espacio del patio (Figs. 11 a 13), invitándole a recorrer visualmente todos sus ángulos y a descubrir los dos hitos funcional y simbólicamente más relevantes, en los que se materializaría el poder absoluto del rey: las qubbas del Cuarto de la Montería ${ }^{44}$ (Fig. 14) y del Cuarto Real Alto (Fig. 15).

La primera de ellas no llegó a ultimarse ${ }^{45}$ y quizá estaría pensada para funcionar como nuevo Salón del Trono en el conjunto general del Alcázar, reproduciendo el esquema espacial del Salón de Embajadores en el palacio de Comares de la Alhambra ${ }^{46}$. Sin embargo, ocuparía una extraña posición oblicua con respecto al ángulo visual del observador para conseguir que todo el énfasis escenográfico del Patio de la Montería se concentrase claramente sobre la portada del palacio de Don Pedro, el elemento con mayor peso visual de todo el conjunto.

Es interesante destacar que, sin duda de forma deliberada, el centro de equilibrio de esa portada se localiza en las tres ventanas lobuladas de la segunda planta, desde las que el monarca podría mostrarse ante sus

\footnotetext{
${ }^{43}$ Almagro Gorbea, 2009, p. 341.

${ }^{44}$ Antonio Almagro identifica las estructuras situadas en el lado Oeste del Patio de la Montería con el Cuarto de la Montería en base a un plano de 1587 que publica Juana Gil-Bermejo (Gil-Bermejo 1973). Almagro Gorbea, 2005, p. 63.

45 Tubino, 1886, p. 90.

46 Almagro Gorbea, 2005, p. 63.
}

súbditos, congregados en el Patio de la Montería, como si de una tribuna se tratase. Por otro lado, es igualmente llamativo que los dos cuerpos laterales de la portada se apreciarían a simple vista como simétricos, aunque el izquierdo es más amplio que el derecho. Esta impresión podría deberse no sólo a la composición central del alzado, sino también a un efecto perceptivo descrito por Arnheim, derivado del hecho de que habitualmente leemos el espacio de izquierda a derecha, por el que si dos objetos iguales se muestran en las mitades izquierda y derecha del campo visual, el de la derecha siempre parece mayor, así que para que parezcan iguales es preciso aumentar el tamaño del de la izquierda ${ }^{47}$.

En la misma obra del psicólogo alemán se describe otra sensación visual que nos refiere cómo para destacar un objeto en una composición artística no es necesario que éste sea grande, ni que esté situado en el centro, sino tan sólo que sea luminoso, ya que la iluminación guía la atención de forma selectiva, en conformidad con el significado pretendido ${ }^{48}$. Podríamos extrapolar este efecto perceptivo a la fachada del palacio de Don Pedro en la que «deslumbran los vivísimos colores y el oro»49, como si emitiese una energía lumínica propia, a pesar de su orientación Norte y no recibir la iluminación directa del sol ${ }^{50}$. Este efecto, luminoso y cromático, serviría para acentuar aún más la importancia simbólica de la fachada en el conjunto palatino sevillano, constituyendo a la vez el refulgente palio para las apariciones públicas del monarca y la lujosa entrada principal a su palacio privado.

\section{El recorrido privado en el interior del palacio [Secuencia 2]}

$\mathrm{Al}$ atravesar la puerta abierta en el centro de la portada del palacio los ojos del observador, impresionados por el sol exterior, tardarían unos instantes en acostumbrarse a la nueva iluminación. El movimiento se ralentizaría, el concepto espacial cambiaría, y el eje visual y de circulación que caracterizaba la zona pública se transformaría

\footnotetext{
47 Arnheim, 2002, p. 48.

48 Ibidem, p. 358- 359.

49 Fernán Caballero, 1862, p. 11.

${ }^{50}$ En las recientes labores de restauración de la fachada se han realizado varios análisis de materiales y recogido diversas muestras de policromía que todavía es necesario procesar hasta obtener datos que permitan proponer hipótesis con las que elaborar un modelo virtual detallado y riguroso, pero que al menos permiten hacernos una idea del color original que la portada exhibiría. Especialmente interesante ha sido el estudio de la policromía del alero, con el que se ha podido constatar un número elevadísimo de repintes sobre el acabado original. Al parecer, en el siglo XIV, el alero ofrecería una composición cromática a base de azules, verdes, rojos, dorados y negro. Ver López Cruz et al., 2011.
} 
en un recorrido quebrado y en penumbra, recuperando el espacio arquitectónico la sensación de intimidad (Figs. 16 y 17).

El hueco de ingreso se ubica en el eje de simetría de un espacio tripartito, constituido por una pieza alargada central separada de otras cuadradas que la flanquean por arcos sobre columnas con capiteles visigóticos. La composición espacial planteada en este punto es reconocible, un salón oblongo con dos alhanías laterales y vano único de acceso al patio al que se asocia, que pudiera acaso interpretarse como un nuevo artificio arquitectónico con el que reforzar la convicción mental de haber ingresado en un edificio palatino residencial. Sin embargo, la naturaleza asimétrica y las particularidades espaciales de estas estancias se hacen rápidamente patentes. Dirigiendo la mirada hacia la derecha encontramos el convencional muro de cierre de la alhanía occidental pero, hacia la izquierda, el espacio se prolonga en una nueva sala separada de la habitación previa por un arco sobre pilastras. La sucesión lineal de los arcos que separan estas habitaciones introduce una tensión perceptiva que dirige instintivamente la vista y el movimiento en esta dirección y enmarca la modesta puerta de acceso a la escalera que conducía al Cuarto Alto como foco de la perspectiva lineal generada (Fig. 18).

Una vez alcanzado el segundo vestíbulo en donde se ubica esta puerta, la atención se desvía ineludiblemente hacia el único foco luminoso de este espacio, una segunda puerta abierta en el centro del muro meridional que marca el umbral de acceso al corredor que conduce hasta el Patio de las Doncellas, provista de una decoración destacada que subraya su importancia dentro de la composición (Fig. 19).

Nos parece importante destacar que el recurso escenográfico desarrollado en torno a esta puerta utiliza los mismos elementos que los presentes en el acceso principal del palacio (hueco, eje, contraste lumínico, etc.), pero persigue un objetivo perceptivo inverso. $\mathrm{Y}$ es que, en lugar de conformar el remate de una composición axial, marcaría el inicio de una nueva, focalizada hacia el fondo luminoso del patio, animando un movimiento hasta ahora ralentizado (Fig. 20). A esta sensación psicológica se uniría además un factor físico, al desarrollarse el corredor de acceso sobre un plano inclinado descendente que, involuntariamente, obligaría al observador a acelerar el paso.

Pensamos que la escasa iluminación de los espacios que se articularían a lo largo de este intrincado itinerario interior conseguiría diluir las impresiones previas, aquellas recreadas en el eje exterior de aproximación al conjunto palaciego, y relajar los sentidos del observador, preparándolo y haciéndolo receptivo a las nuevas sensaciones que experimentaría al llegar al Patio de las Doncellas, auténtico núcleo vertebrador del palacio privado, el espacio donde se concentraría la mayor intensidad perceptiva de todo el palacio.

La entrada al mismo se localiza en su esquina Noroeste, con lo que la primera imagen que se tiene de él es una vista tangencial, que provoca casi irremediablemente que la mirada del observador gire hacia la derecha y se detenga sobre el volumen emergente de la Sala de la Media Naranja (Fig. 21). Dispuesto en el extremo occidental del eje principal del patio, ayudaría a definir claramente la dirección de lectura del espacio, alzándose como referencia visual principal. Además, al introducir una componente vertical, ascendente, central, simétrica y dinámica en una composición general caracterizada por la horizontalidad y el estatismo, subrayaría la importancia simbólica de la qubba, espacio regio por antonomasia, sirviendo como fórmula arquitectónica para materializar el poder y la grandeza del monarca.

Como se desprende de una observación cuidadosa, el Patio de las Doncellas presenta una disposición simétrica únicamente respecto a su eje longitudinal, aunque aparentemente pueda parecerlo también en dirección transversal. El efecto se debe a la armonía de los pórticos perimetrales y a la equilibrada disposición del jardín rehundido con la alberca, elementos éstos que suministran nexos comunes, útiles para articular piezas discordantes. Por ejemplo, la particular forma en doble $\mathrm{T}$ de la alberca ayudaría a enfatizar la importancia de los lados menores y a homogeneizar su apariencia, y su lámina de agua actuaría como espejo de la arquitectura, creando nuevas simetrías irreales, estableciendo una particular fluidez espacial (Fig. 22).

Otro de los elementos que insistiría en este mismo efecto sensitivo sería el alero continuo que recorrería los cuatro alzados del patio, al establecer claramente la frontera física entre dos conceptos arquitectónicos diferentes. Por debajo del alero, se haría presente el espacio perceptivamente homogéneo al que nos referíamos anteriormente, por encima, sobresaldría una planta alta que carecería probablemente de esa uniformidad, recibiendo un tratamiento distinto en cada uno de sus frentes ${ }^{51}$, con

\footnotetext{
51 Según las hipótesis reconstructivas realizadas por Antonio Almagro, la planta alta del palacio sólo se extendería sobre determinadas partes de las crujías Norte y Sur del palacio. Casi todas las estancias tendrían carácter de habitaciones privadas, a excepción de una qubba y sus espacios anexos, construidos sobre el vestíbulo y pensados para funcionar, probablemente, como salón de recepciones. Almagro Gorbea, 2005, p. 59.
} 


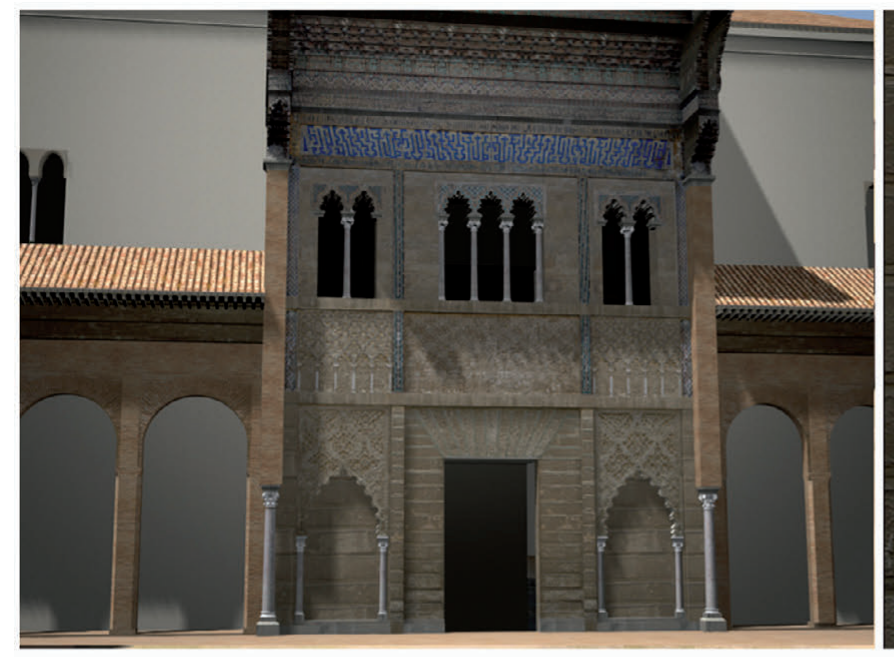

Figura 16

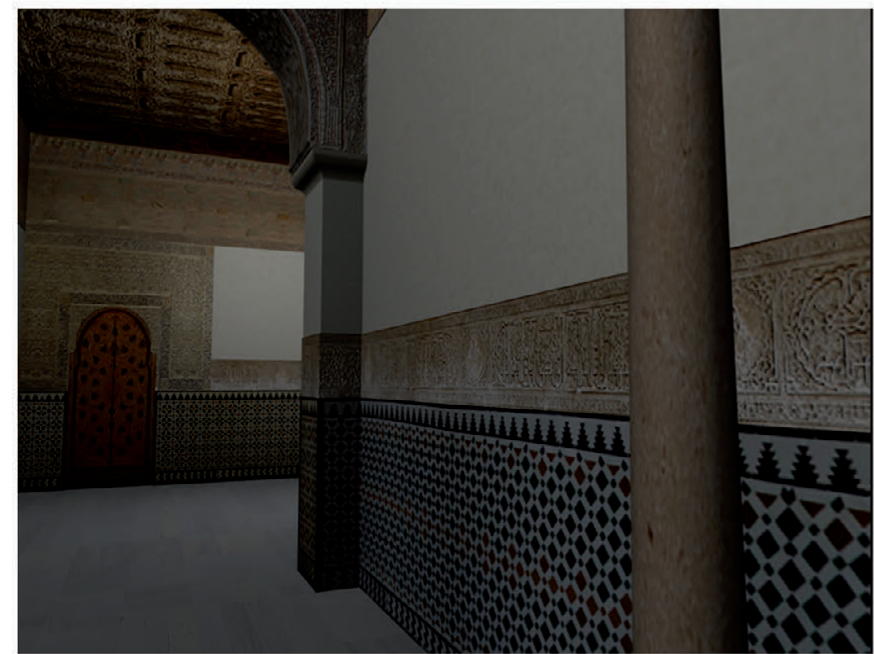

Figura 18

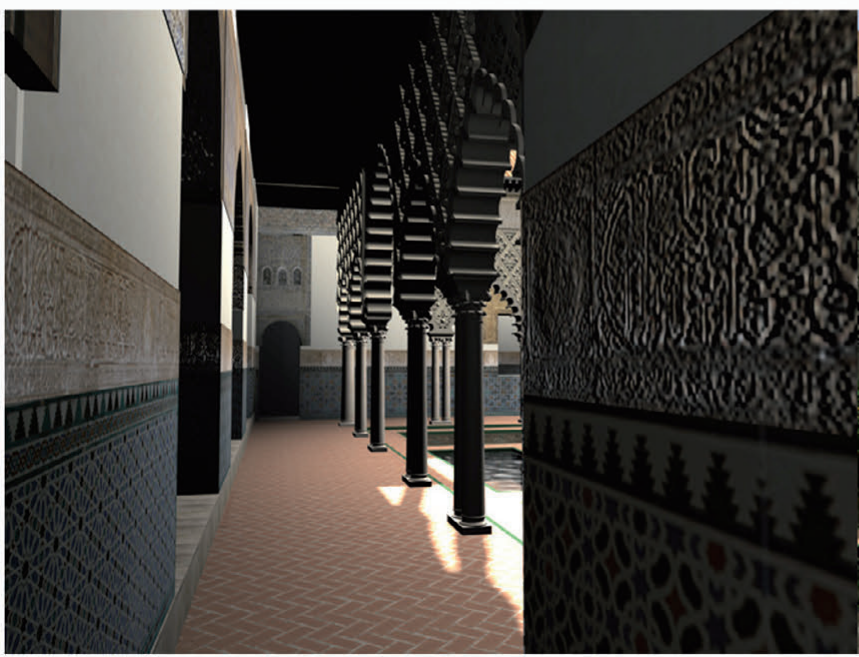

Figura 20

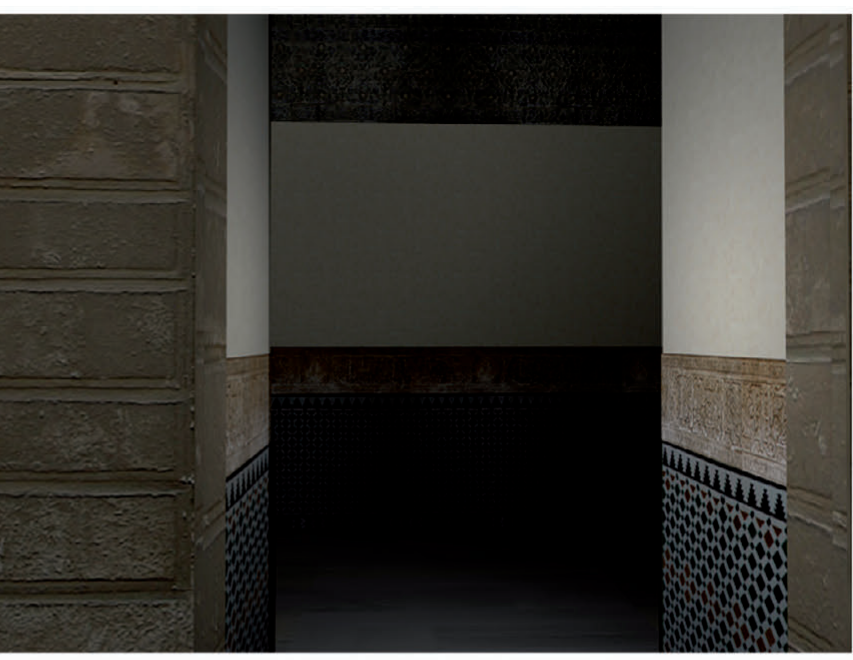

Figura 17

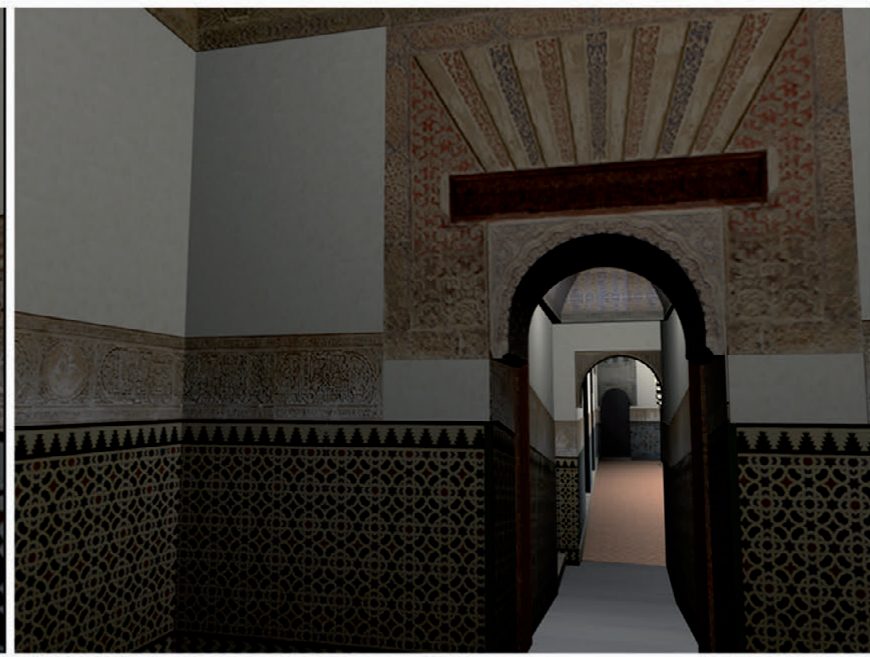

Figura 19

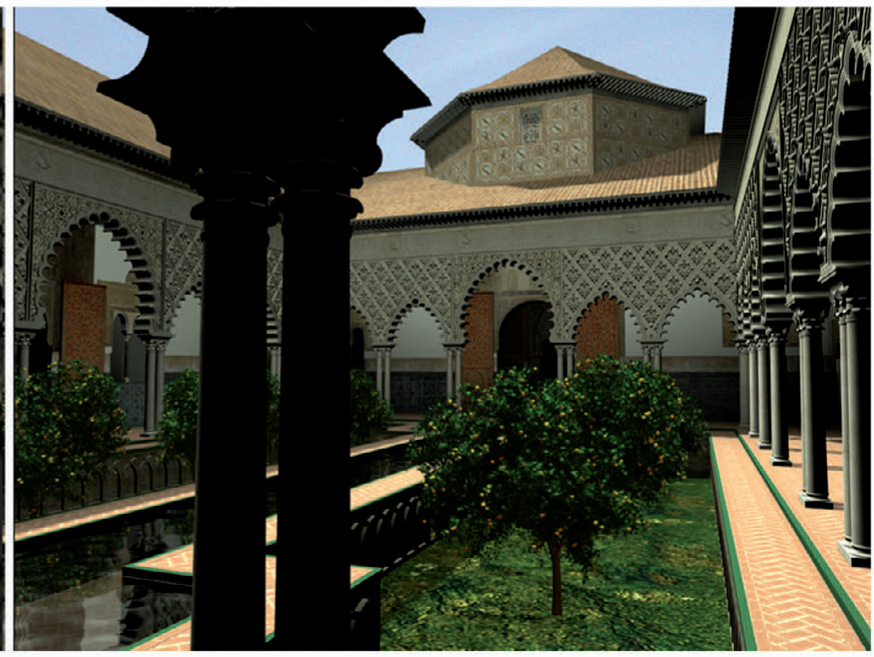

Figura 21

Figuras 16 a 21 [Secuencia 2]: El recorrido privado en el interior del palacio 


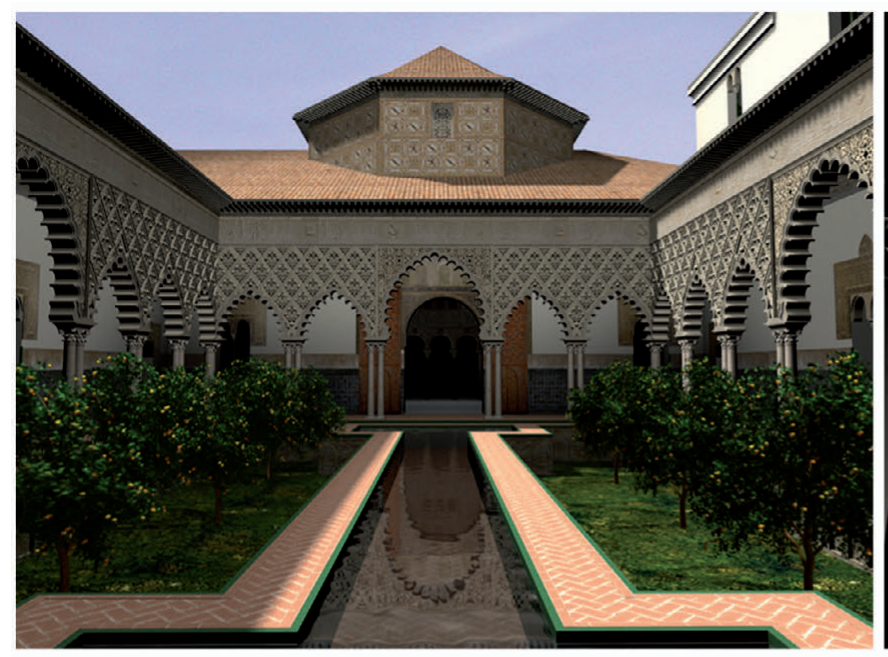

Figura 22

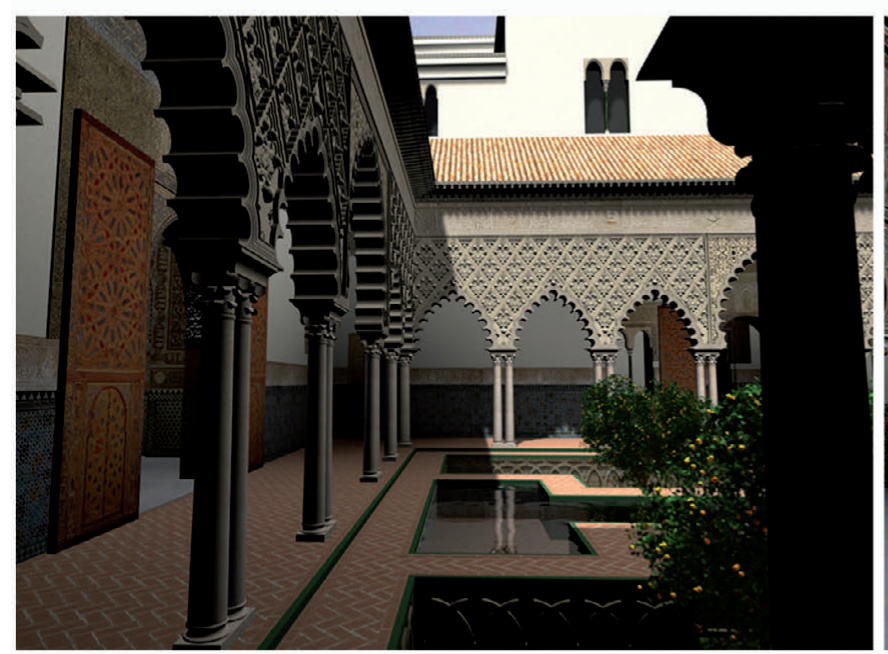

Figura 24

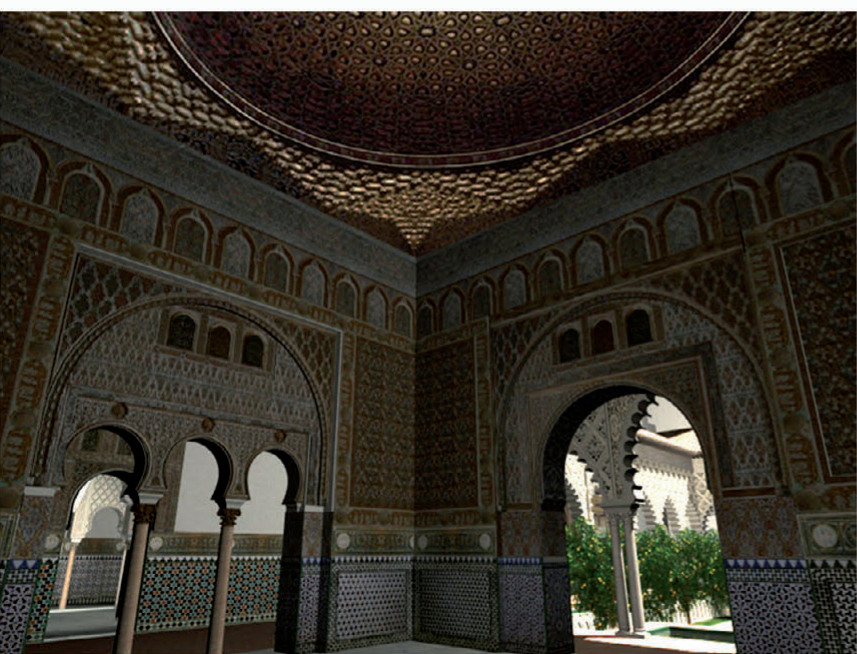

Figura 26

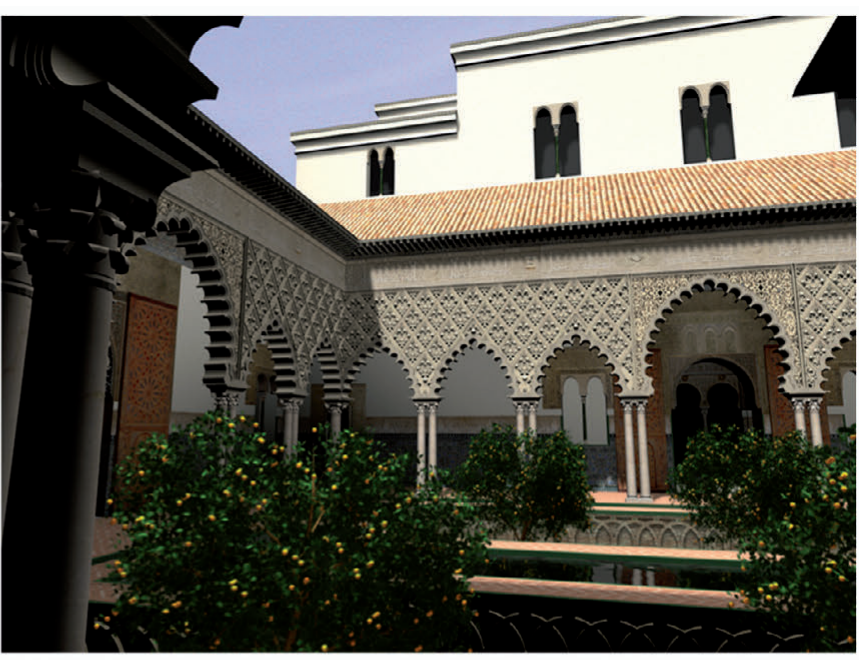

Figura 23

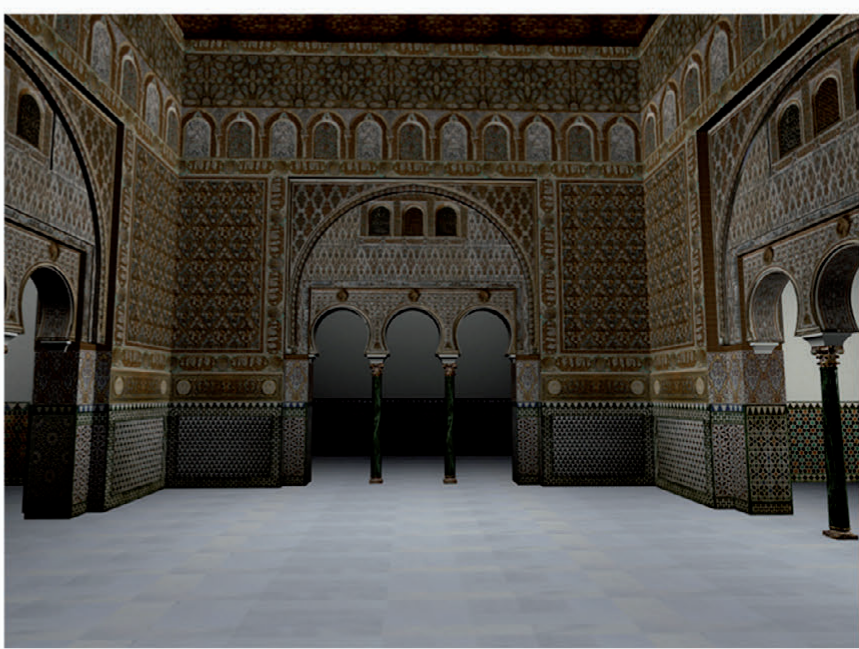

Figura 25

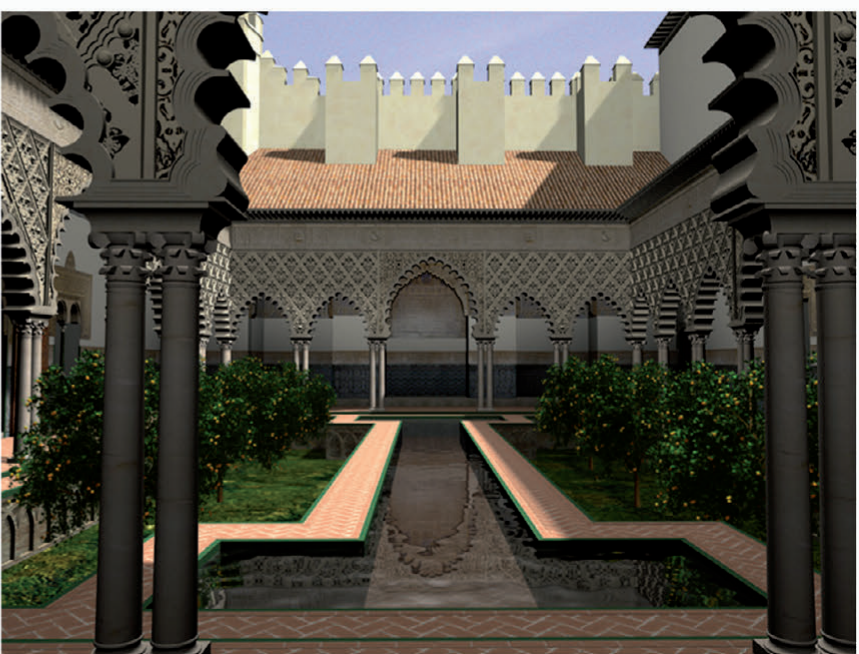

Figura 27

Figuras 21 a 27 [Secuencia 2]: El recorrido privado en el interior del palacio 
volúmenes que exhibirían una mayor o menor riqueza decorativa y ocuparían posiciones más o menos centradas en el conjunto en función de su jerarquía simbólica y de las actividades cobijadas en su interior.

Dejando a un lado el volumen de la qubba de la Media Naranja, al que nos referíamos en párrafos anteriores, uno de los más interesantes es el correspondiente al Cuarto Real Alto, que se ubicaría en la crujía septentrional del palacio y estaría formado por dos crujías ideadas para dar respuesta a dos funciones y dos composiciones perceptivas diferentes (Fig. 23). La crujía orientada al Norte cobijaría el Salón de Recepción Alto. Su función protocolaria se haría claramente ostensible hacia el Patio de la Montería, a través de la magnífica fachada del palacio y del solemne volumen de su qubba, que sobresaldría por encima del resto de elementos de aquel patio, situado en la zona pública del Alcázar. Sin embargo, debido a sus particulares proporciones compositivas, este espacio no sería visible desde el Patio de las Doncellas, apreciándose únicamente el volumen de la crujía meridional, en donde se localizaría un salón oblongo con menor altura y contundencia perceptiva, quizá con función residencial ya que por su orientación meridional debía de ser uno de los lugares más cálidos del palacio.

Aunque nada podemos asegurar en cuanto a su decoración o acabados, pensamos que el aspecto exterior de esta pieza sería austero y simétrico, para evitar que su excesivo peso visual restase ligereza a los pórticos de la planta baja o que la atención se desviase del nivel inferior del patio, donde las puertas de acceso a la Alcoba del Rey o la Sala de la Media Naranja concentrarían un mayor esfuerzo decorativo y escenográfico (Fig. 24).

Precisamente siguiendo el recorrido en torno al Patio de las Doncellas llegaríamos hasta la segunda de estas puertas. El espacio interior de la qubba de la Media Naranja, misteriosamente iluminado por tenues reflejos dorados, atraería poderosamente la curiosidad del observador e invitaría a éste a desplazarse hacia su interior (Fig. 25). Una vez dentro, la centralidad de la estructura, su decoración y sobre todo su remate mediante una "espléndida cúpula» ${ }^{52}$, conferirían a este espacio un carácter cósmico, utópico e ideal, reflejo del poder del soberano y de la nueva concepción del Estado.

Los efectos lumínicos creados en él serían interesantísimos. Recordemos que, en época medieval, tanto

\footnotetext{
52 Esta frase aparece en las inscripciones árabes del portalón izquierdo del Salón de la Media Naranja. Cano y Essawi, 2004, p. 67.
}

para musulmanes como para cristianos la luz constituye: «la cualidad estética primordial y la más cercana a la sustancia divina» ${ }^{53}$. Por eso, aunque la qubba es percibida desde el exterior como un ámbito en penumbra, interiormente nos descubre una riquísima variedad de luces indirectas, procedentes de lugares estratégicos, que generarían determinadas ilusiones visuales e introducirían ciertas connotaciones simbólicas (Fig. 26).

Por ejemplo, la relativa oscuridad reinante en este salón, en contraste con la intensa luminosidad del patio, permitiría percibir el efecto aéreo del techo, constituido quizá por una cúpula dorada similar a la actual ${ }^{54}$, que parecería brillar con luz propia. Por otro lado, una serie de focos luminosos secundarios, no perceptibles hasta penetrar en el espacio de la qubba, determinarían un segundo eje compositivo importante dentro del palacio, perpendicular al que regía la organización y trazado del patio de las Doncellas. Este eje transversal hilvanaría, de Norte a Sur, los espacios correspondientes al Dormitorio del Príncipe, el Patio de las Muñecas, la Sala de la Media Naranja y sus salas colaterales, y las habitaciones de los Infantes. Parece evidente que los artistas que idearon estos espacios concibieron sofisticadas perspectivas interiores, creando así verdaderas escenografías que ofrecerían la sensación de continuidad espacial y una incesante sorpresa perceptiva.

Por último, también desde el interior de esta sala, sería posible percibir en su totalidad el alzado Este del Patio de las Doncellas, el más sencillo formal y conceptualmente aunque, no en vano, dotado de gran belleza perceptiva. En él, el pórtico simplemente se adosa al muro que separa el palacio de Don Pedro de las salas del patio del Crucero, reaprovechando los contrafuertes de la construcción gótica y sus espacios intermedios para generar una ingeniosa articulación de formas y volúmenes (Fig. 27). De nuevo el alero sirve como línea divisoria entre dos tipos de arquitectura: funcional y austera la gótica, sensible y recóndita la andalusí. Así, la parte superior dejaría traslucir las formas desnudas y netas de almenas y torres y la inferior, la riqueza expresiva de

\footnotetext{
53 Rodríguez, 2008: 108-109.

${ }^{54}$ No se sabe con seguridad cómo sería la cúpula original. Tradicionalmente se ha atribuido la cúpula actual al maestro mayor de carpintería de Juan II, Diego Ruiz, que la realizaría en 1427. Esta fecha viene dada por Félix González de León, que al parecer pudo ver en 1844 una inscripción que así lo aseguraba. Sin embargo, en la reciente restauración de la cúpula, en la que se han inspeccionado minuciosamente todos los elementos, el equipo de restauración no ha encontrado la inscripción referida por este cronista sevillano. Ver Candelas, 2001, p. 37.
} 
tres nichos profusamente decorados, rematados superiormente por hermosos arcos de mocárabes. Sin embargo y a pesar del evidente contraste, la transición de una a otra se percibe como algo sereno, equilibrado y suave, permitiendo la convivencia armónica de las dos estéticas más representativas de los palacios cristianos medievales hispanos.

Creemos ver en este recurso arquitectónico cierto trasfondo simbólico. No nos cabe duda de que Alfonso X sirvió a Don Pedro como modelo ideológico. Uno y otro buscaron la implantación del centralismo político a través de la unificación jurídica y el desarrollo de la Administración. Alfonso X defendía también que sólo el príncipe tiene capacidad para elaborar leyes y, consecuentemente, todos los súbditos están obligados a aceptarlas, correspondiendo al rey las alegaciones judiciales en última instancia ${ }^{55}$. Pero además, ambos soberanos compartieron su admiración por la cultura musulmana y judía. Quizá la inclusión visual del palacio gótico alfonsí en el núcleo principal de la nueva residencia privada de Don Pedro, el Patio de las Doncellas, en una composición que parece pensada para ser percibida desde el espacio de mayor importancia simbólica del mismo, la Sala de la Media Naranja, pudiera considerarse un homenaje del rey castellano al que fue, durante gran parte de su reinado, heredero al Sacro Imperio RomanoGermánico, constatando así no sólo la conformidad con el ideario político de su bisabuelo sino también la legitimidad dinástica de su poder.

\section{CONCLUSIÓN}

A pesar de la pluralidad de descripciones e interpretaciones que podrían derivarse de la riqueza de matices inherente a los espacios arquitectónicos, los análisis y estudios de arquitecturas transformadas o desaparecidas suelen a menudo limitarse a unas planimetrías más o menos rigurosas, acompañadas de unos artículos en los que se explican las hipótesis reconstructivas que las han generado.

En otras ocasiones, se realizan fantásticas reconstrucciones virtuales con gran potencial y atractivo visual. Sin duda ofrecen nuevas y valiosísimas posibilidades de análisis pero, a pesar de que con ellas se consigue evocar, al menos en parte, las sensaciones que aquella arquitectura histórica suscitaría entre los obser-

\footnotetext{
55 Partida II, Título I, Ley II del libro Las Siete Partidas, cuerpo normativo redactado por Alfonso X con el objetivo de conseguir cierta uniformidad jurídica en el reino de Castilla.
}

vadores de su tiempo, son pocas las ocasiones en las que el espacio arquitectónico se interpreta o valora a partir de ellas ${ }^{56}$.

La reconstrucción virtual de la arquitectura histórica permite elaborar distintas variantes de una misma hipótesis, compararlas entre sí y verificar sus posibilidades y su probabilidad pero, para el arquitecto, tiene un valor añadido porque, a través de ella, las impresiones espaciales se hacen evidentes y las condiciones de iluminación pueden comprobarse. El montaje mental que puede realizarse al articular imágenes animadas con sus respectivas representaciones planas en planta, sección y alzado ayuda no sólo a comprender el proyecto hasta sus más pequeños detalles, sino que provoca la recreación de una experiencia secuencial que conjunta perfectamente espacio y tiempo y que permite entender la experiencia perceptiva que esos espacios arquitectónicos generarían originalmente en el espectador. Sin embargo, no todos los espacios arquitectónicos son igualmente relevantes. En este sentido, pensamos que la utilización de las herramientas propias de la "space syntax" puede ayudarnos a hallar la secuencia espacioperceptiva más adecuada para un análisis como el que planteamos.

Aplicando estas premisas teóricas a un caso concreto, el Alcázar de Sevilla en el siglo XIV, creemos haber profundizado en torno al por qué y al cómo fueron ideados y construidos algunos de los espacios medievales de este conjunto monumental. Así, parece comprobarse que el proyecto palatino diseñado por los arquitectos y artistas que trabajaron al servicio de Pedro I de Castilla pretendía crear un escenario arquitectónico que transmitiese a los súbditos el poder, la supremacía y la legitimidad reales en un momento políticamente delicado para este monarca y, al mismo tiempo, erigir la arquitectura más bella de todas las alzadas hasta entonces, valiéndose de interesantes recursos perceptivos y compositivos.

Gracias a las teorías modernas de la Psicología de la Percepción o el Análisis de Formas Arquitectónicas y a los conceptos acuñados por éstas, podemos decir que la ordenación física del espacio de la entrada axial al Alcázar atendería al planteamiento perceptivo de una visión seriada, una noción ligada habitualmente a la escala urbana, que en el conjunto sevillano medieval serviría para ennoblecer y expandir sensitivamente el

\footnotetext{
${ }^{56}$ A este respecto es especialmente significativo el libro de Almagro Vidal (2008).
} 
nuevo acceso al palacio real. Creemos descubrir también cómo se acude reiteradamente al recurso perceptivo del contraste para acentuar determinados elementos simbólicamente importantes dentro de este recorrido protocolario de aproximación al monarca: la puerta de la Montería, la fachada real y el Salón de Recepciones situado en la planta alta de la misma, el momento en que se produce la transición entre la zona pública y la privada del conjunto, etc.

Asímismo, en base al análisis realizado, estimamos que la experiencia sensitiva que pretendería generarse en el interior del palacio privado de Don Pedro sería muy diferente a la que suscitarían los ámbitos espaciales que compondrían el acceso monumental al mismo. Creemos que el mensaje perceptivo sería conscientemente distinto porque se dirigiría a interlocutores distintos: no serían simples súbditos sino personajes con la dignidad suficiente como para ser recibidos por el monarca en su residencia privada. Para ellos, para los más allegados al rey y para el propio soberano, la arquitectura se tornaría pródiga en matices, íntima y sorprendente. La luz, la sombra y la penumbra, la simetría, la decoración, la vegetación o el agua serían ahora protagonistas, y pensamos que las bellas composiciones que el uso acertado de todos estos recursos producirían, estarían ideadas para provocar el deleite y disfrute de todos los sentidos.

Como consideración final, nos gustaría señalar que somos conscientes de que lo que vemos, descubrimos, reconocemos y sentimos gracias a estas evocaciones virtuales no puede describirse o explicarse en su totalidad, y de que las investigaciones que dirigen su interés al análisis sensitivo de cualquier realización arquitectónica se enfrentan a problemas como los de la subjetividad o la contaminación ideológica en la interpretación, al no ser fácil eludir el bagaje propio de experiencias, emociones, conceptos e ideas, pero creemos firmemente que el análisis espacial y perceptivo de la arquitectura histórica amplía la visión y los medios analíticos del investigador, mejorando sustancialmente su comprensión del Patrimonio Arquitectónico. Por ello pensamos que, en el seno de la disciplina de la Arqueología de la Arquitectura, lo realizado con la reconstrucción virtual del palacio medieval de Pedro I en los Reales Alcázares de Sevilla podría aplicarse, muy provechosamente, a otros referentes arquitectónicos.

\section{ANEXO}

Se acompaña un vídeo en la versión html on-line.

\section{BI BLI OGRAFÍ A}

Almagro Gorbea, A. 2000: Planimetría del Alcázar de Sevilla. CSIC-Escuela de Estudios Árabes y Ayuntamiento de Sevilla-Patronato del Real Alcázar, Granada y Sevilla.

Almagro Gorbea, A. 2003: "De la fotogrametría a la infografía. Un proceso informatizado de documentación”, en García Porras, A. (ed.), Informática y Arqueología medieval, pp. 47-81. Universidad de Granada, Granada.

Almagro Gorbea, A. 2005: "La recuperación del jardín medieval del Patio de las Doncellas”, Apuntes del Alcázar de Sevilla, 6, pp. 44-67.

Almagro Gorbea, A. 2006: "El Alcázar de Sevilla en el siglo XIV”, en Viguera, M. J. (ed.), Ibn Jaldún. El Mediterráneo en el siglo XIV. Auge y declive de los imperios, pp. 398-403. Fundación El Legado Andalusí, Granada y Sevilla.

Almagro Gorbea, A. 2007a: "Una nueva interpretación del Patio de la Casa de Contratación del Alcázar de Sevilla”, Al-Qantara, XXVIII-l, pp. 181-228.

Almagro Gorbea, A. 2007b: “Los Reales Alcázares de Sevilla”, Artigrama, 22, pp. 155-185.

Almagro Gorbea, A. 2009: "La portada del palacio de Pedro I. Investigación y restauración”, Apuntes del Alcázar de Sevilla, 10, pp. 6-49.

Almagro Vidal, A. 2008: El concepto de espacio en la arquitectura palatina andalusí: un análisis perceptivo a través de la infografia. CSIC, Madrid.

Arnheim, R. 2002: Arte y percepción visual: psicología del ojo creador, nueva versión. Alianza Editorial, Madrid.

Asín Palacios, M. 1935: La espiritualidad de Algazel y su sentido cristiano. Instituto Arias Montano, Madrid.

Batty, M. 2004: “A New Theory of Space Syntax”, CASA Working Paper, 75, pp. 1-34 [en línea] http://www.casa.ucl.ac.uk/working_papers/paper75.pdf

Beardsley, M. C. y Hospers, J. 1997: Estética: historia y fundamentos. Ed. Cátedra, Madrid.

Bermejo Tirado, J. 2009: "Leyendo los espacios: una aproximación crítica a la sintaxis espacial como herramienta de análisis metodológico”, Arqueología de la Arquitectura, 6, pp. 47-62. doi: 10.3989/arqarqt.2009.09004.

Braaksma, J. P. y Cook, W. J. 1980: "Human orientation in transportation terminals”, Transportation Engineering Journal, 106, pp. 189-203.

Candelas Gutiérrez, A. 2001: “Geometría y proceso constructivo de la cúpula del Salón de Embajadores”, Apuntes del Alcázar, 2, pp. 36-76.

Cano Ávila, P. y Essawi, A. T. M. 2004: “Estudio epigráfico-histórico de las inscripciones árabes de los portalones y ventanas del Patio de las Doncellas del Palacio de Pedro I en el Real Alcázar de Sevilla”, Apuntes del Alcázar de Sevilla, 5, pp. 52-79.

Caro, R. 1634: Antigüedades y Principado de la Ilustrísima ciudad de Sevilla y Chorographia de su convento jurídico o antigua cancillería. A. Grande, Sevilla.

Cómez Ramos, R. 1989: "La puerta del rey don Pedro en el patio del León del Alcázar de Sevilla”, Laboratorio de Arte, 2, pp. 3-14.

Cómez Ramos, R. 1996: El Alcázar del rey Don Pedro. Diputación de Sevilla, Sevilla.

Cómez Ramos, R. 2006: “Iconología de Pedro I de Castilla”, Historia, Instituciones, Documentos. Revista del Departamento de Historia Medieval de la Universidad de Sevilla, 33, pp. 61-80.

Cómez Ramos, R. 2008: “El Alcázar del rey Pedro I de Castilla en Sevilla como espacio intercultural en el contexto de la arquitectura mudéjar de su tiempo”, Mitteilungen der Carl Justi-Vereinigung, 20, pp. 48-64.

Cullen, G. 1974: El Paisaje Urbano. Tratado de Estética Urbanística. Ed. Blume, Barcelona.

Chávez González, M. R. 2004: El Alcázar de Sevilla en el siglo XIX. Patronato del Real Alcázar de Sevilla, Sevilla.

Ching, F. 2012: Arquitectura: forma espacio y orden. Ed. Gustavo Gili, México.

Díaz Estrella, A. 2011: “Inmersión mental y realidad virtual”, Uciencia, 6, pp. 30-33.

Díaz Martín, L. V. 1997: Un rey sevillano: Don Pedro I de Castilla (13501369). Área de Cultura, Ayuntamiento de Sevilla, Sevilla.

Dondis, D. 1992: La sintaxis de la imagen. Introducción al alfabeto visual. Ed. Gustavo Gili, Barcelona. 
Eco, H. 1997: Arte y belleza en la estética medieval. Ed. Lumen, Barcelona. Estow, C. 1995: Pedro the Cruel of Castile, 1350-1369. E. J. Brill, Leiden.

Faulkner, P.A. 1964: "Castle planning in the fourteenth century", The Archaeological Journal, CXX, pp. 215-235.

Fernán Caballero [Böhl de Faber, C.] 1862: El Alcázar de Sevilla. La Andalucía, Sevilla.

Fernández Ruiz, J. A. y González Garrido, M. 2002: “La representación del patrimonio desaparecido: el Patio del Crucero del Alcázar de Sevilla”, en Actas del IX Congreso Internacional de Expresión Gráfica Arquitectónica, EGA 2002, pp. 517-522. Universidade da Coruña, Departamento de Representación y Teoría Arquitectónicas, La Coruña.

Foster, S. 1989: “Analysis of spatial patterns in buildings (access analysis) as an insight into social structure: examples from the Scottish Atlantic Iron Age”, Antiquity, 63, pp. 40-50.

Gestoso y Pérez, J. 1889: Sevilla monumental y artística. El Conservador, Sevilla.

Gil-Bermejo García, J. 1973. "La Casa de Contratación de Sevilla (Algunos aspectos de su historia)”, Anuario de Estudios Americanos, XXX. pp. 679-761.

González de León, F. 1844: Noticia artística, histórica y curiosa de todos los edificios públicos, sagrados y profanos de esta muy noble ciudad de Sevilla. J. Hidalgo, Sevilla.

Hillier, B. y Hanson, J. 1984: Social logic of space. Cambridge University Press, Cambridge.

López Cruz, O., García Bueno, A. y Medina Flórez, V. J. 2011: “Evolución del color en el alero de la fachada del rey D. Pedro I, Real Alcázar de Sevilla. Aportaciones del estudio de materiales a la identificación de las intervenciones de restauración a lo largo de su historia”, Arqueología de la Arquitectura, 8, pp. 163-178. doi: 10.3989/arqarqt.2011.10012.

López de Ayala, P. 1779. Crónica de los Reyes de Castilla Don Pedro, Don Enrique II, Don Juan I, Don Enrique III. A. de Sancha, Madrid.

Mañana Borrazas, P. 2003: “Arquitectura como percepción”, Arqueología de la Arquitectura, 2, pp. 177-183.

Marín Fidalgo, A. 1990: El Alcázar de Sevilla bajo los Austrias. Ed. Guadalquivir, Sevilla.

Marín Fidalgo, A. 2006: El Real Alcázar de Sevilla bajo los Borbones. El reinado de Felipe V (1700-1746). Ed. Guadalquivir, Sevilla.

Moya, G. 1974: Don Pedro el Cruel. Biología, política y tradición literaria en la figura de Pedro I de Castilla. Ed. Júcar, Madrid.

Puerta Vílchez, J. M. 1997: Historia del pensamiento estético árabe: AlÁndalus y la estética árabe clásica. Ed. Akal, Madrid.
Quirós Castillo, J. A. 2002: “Arqueología de la Arquitectura en España”, Arqueología de la Arquitectura, 1, pp. 27-38.

Rasmussen, S. E. 1964: Experiencing Architecture. Massachusetts Institute of Technology Press, Cambridge.

Real Academia Española 2001. Diccionario de la lengua española (22. a ed.). [en línea] http://www.rae.es/rae.html.

Rodríguez Zahar, L.2008: Arte islámico, evocación del paraíso: doctrina, lenguaje y temas iconográficos. Ed. El colegio de México, Centro de Estudios de Asia y África, México D.F.

Schmarsow, A. 1894: Das Wesen der architektonischen Schöpfung. Antrittsvorlesung, gehalten in der Aula der K. Universität Leipzig am 8. November 1893. K. W. Hiersemann, Leipzig.

Seguró Mendlewicz, M. 2008: “Trazos de estética medieval”, Revista Española de Filosofia Medieval, 15, pp. 137-148.

Susperregui, J. M. y Arranz, R. 2007: “El paradigma tecnológico como método de observación y análisis del cine”, en Marzal Felici, J. y Gómez Tarín, F. J. (eds.), Metodologías de análisis del film. Actas del I Congreso Internacional sobre Análisis Fílmico, pp. 49-56. Ed. Edipo, Madrid.

Tabales Rodríguez, M. A. 2001: "El palacio islámico localizado bajo el patio de la Montería del Alcázar de Sevilla”, en Anuario Arqueológico de Andalucía 1997, pp. 224-241. Junta de Andalucía, Sevilla.

Tabales Rodríguez, M. A. 2003: "Investigaciones arqueológicas en el Patio de las Doncellas”, Apuntes del Alcázar de Sevilla, 4, pp. 7-25.

Tabales Rodríguez, M. A. 2005: "El Patio de las Doncellas del Palacio de Pedro I de Castilla. Génesis y Transformación”, Apuntes del Alcázar de Sevilla, 6, pp. 7-43.

Tabales Rodríguez, M. A. 2006: “Investigaciones arqueológicas en el Patio del León”, Apuntes del Alcázar de Sevilla, 7, pp. 6-39.

Tabales Rodríguez, M. A. 2010: El Alcázar de Sevilla. Reflexiones sobre su origen y transformación durante la Edad Media: memoria de investigación arqueológica 2000-2005. Consejería de Cultura de la Junta de Andalucía, Sevilla.

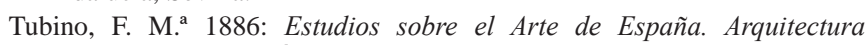
Hispano-visigoda y Árabe española. El Alcázar de Sevilla. Una iglesia mozárabe. C. Segovia de los Ríos, Sevilla.

Wilber, D. y Golombek, L. 1988: The Timurid Architecture of Iran and Turan. Princeton University Press, Princeton.

Zevi, B. 1991: Saber ver la arquitectura, ensayo sobre la interpretación espacial de la arquitectura. Ed. Poseidón, Buenos Aires. 